\title{
Four new species of Brueelia Kéler, 1936 (Phthiraptera: Ischnocera) from African hosts, with a redescription of Nirmus bicurvatus Piaget, 1880
}

\author{
Daniel R. GUSTAFSSON ${ }^{1, *}$, Fasheng ZOU ${ }^{2}$, Lucie OSLEJSKOVA ${ }^{3}$, \\ Tomas NAJER ${ }^{4} \&$ Oldřich SYCHRA ${ }^{5}$ \\ 1,2 Guangdong Key Laboratory of Animal Conservation and Resource Utilization, Guangdong \\ Public Laboratory of Wild Animal Conservation and Utilization, Guangdong Institute of Applied \\ Biological Resources, 105 Xingang West Road, Haizhu District, Guangzhou 510260, China. \\ ${ }^{3,5}$ Department of Biology and Wildlife Diseases, Faculty of Veterinary Hygiene and Ecology, \\ University of Veterinary and Pharmaceutical Sciences, \\ Palackeho tr. 1946/1, 61242 Brno, Czech Republic. \\ ${ }^{4}$ Department of Veterinary Sciences, Faculty of Agriculture, Food and Natural Resources, \\ Czech University of Life Sciences, Kamycka 129, 16500 Prague 6, Czech Republic. \\ *Corresponding author: kotatsu@fripost.org \\ 22Email: zoufs@gdei.gd.cn \\ ${ }^{3}$ Email: 1.oslejskova@gmail.com \\ ${ }^{4}$ Email: tomas.najer@gmail.com \\ ${ }^{5}$ Email: sychrao@vfu.cz

\footnotetext{
${ }^{1}$ urn:1sid:zoobank.org:author:19BFE360-6665-4A1B-89DC-33E5D5AC6C39

${ }^{2}$ urn:Isid:zoobank.org:author:A0E4F4A7-CF40-4524-AAAE-60D0AD845479

${ }^{3}$ urn:1sid:zoobank.org:author:36F9FB69-004F-4FC2-A08E-7CD9CF0104DA

${ }^{4}$ urn:lsid:zoobank.org:author:08A25BDD-8CCD-4709-9A57-7CE235D473C7

${ }^{5}$ urn:lsid:zoobank.org:author:D28CEAFB-0F34-4937-A66E-6AC8BA90E325
}

\begin{abstract}
Four new species of Brueelia Kéler, 1936 are described and illustrated. All of them parasitize African endemic host species in the families Passeridae, Ploceidae, and Estrildidae (Passeriformes). They are: Brueelia pofadderensis sp. nov. ex Passer melanurus damarensis Reichenow, 1902 and P. m. vicinus Clancey, 1958; B. semiscalaris sp. nov. ex Granatina granatina (Linnaeus, 1758); B. sima sp. nov. ex Malimbus nitens (Gray, 1831); B. terpsichore sp. nov. ex Euplectes jacksoni (Sharpe, 1891) and E. progne delamerei (Shelley, 1903). In addition, Brueelia bicurvata (Piaget, 1880) is redescribed and reillustrated from non-type material. A summary of all published records of lice in the Brueelia complex from Africa since 1980 is provided. We also estimate the unknown diversity of African species of Brueelia based on an index of host specificity calculated for each host family independently. The unknown diversity is estimated to be over 1000 species of Brueelia from African hosts, compared to the $<50$ species in this genus currently recorded from Africa.
\end{abstract}

Keywords. Phthiraptera, new species, Brueelia complex, species diversity, host specificity. 
Gustafsson D.R., Zou F., Oslejskova L., Najer T. \& Sychra O. 2019. Four new species of Brueelia Kéler, 1936 (Phthiraptera: Ischnocera) from African hosts, with a redescription of Nirmus bicurvatus Piaget, 1880. European Journal of Taxonomy 507: 1-48. https://doi.org/10.5852/ejt.2019.507

\section{Introduction}

The chewing lice of African songbirds have long been poorly known (Ledger 1980; Gustafsson \& Bush 2015; Light et al. 2016; Takano et al. 2017, 2018). In particular, very few species of lice belonging to the Brueelia complex (sensu Gustafsson \& Bush 2017) have ever been reported from Africa. In his summary of the chewing lice known from sub-Saharan Africa, Ledger (1980) listed only 3 species of Meropoecus Eichler, 1940, 36 species of Brueelia Kéler, 1936 and 16 species of Sturnidoecus Eichler, 1944 (note that Ledger overlooked the many African species of Sturnidoecus described in Ansari 1968). Of these, only 25 species have been recorded from birds that breed in sub-Saharan Africa; the remaining lice in the list in Ledger (1980) concern species known from hosts that migrate to Africa from Eurasia. In at least some cases, this list includes species of lice that have never been recorded in sub-Saharan Africa, but which occur on hosts that migrate to this region.

In recent decades, many new records of lice in the Brueelia complex have been published from African countries (e.g., Balakrishnan \& Sorenson 2006; Sychra et al. 2010a, 2010b; Najer et al. 2012; Gustafsson \& Bush 2015, 2017; Bush et al. 2016; Light et al. 2016; Takano et al. 2017, 2018; Gustafsson et al. 2018). However, in many of these reports, lice of the Brueelia complex have not been identified to species level, and few new species of lice in this complex have been described from Africa since 1980 (Fig. 1; Appendix). Data from several published phylogenies that include African lice of the Brueelia complex (Bush et al. 2016; Light et al. 2016; Takano et al. 2017, 2018) and from a morphological survey (D.R. Gustafsson and S.E. Bush, unpublished data) show that the diversity of lice in this complex is very high in Africa, and a vast number of species remain undescribed. The lack of descriptions, illustrations and identification keys for African lice of the Brueelia complex limits our understanding of the biogeography and evolution of these lice and their host associations.

Here, we provide descriptions of four new species of Brueelia from Africa, as well as a redescription of Nirmus bicurvatus Piaget, 1880. All five species treated here are from host species that are endemic to Africa, and all five hosts belong to families that are very speciose in this region.

\section{Material and methods}

All material examined is deposited as slide-mounted specimens at the Natural History Museum, London (NHML). Specimens were examined in an Olympus CX31 microscope. Illustrations were drawn by hand, using a drawing tube fitted to the microscope. Line drawings were scanned, collated and edited in GIMP (www.gimp.org). Grey lines in all illustrations denote the approximate extent of dark pigmentation; note that these patterns typically differ slightly between specimens of the same species, and sometimes between sides of the same specimen.

Measurements were made from photographs in Quick Photo Micro ver. 3.1 (Promicra, Prague, Czech Republic) and are given for the following dimensions (in $\mathrm{mm}$ ):

$$
\begin{aligned}
\mathrm{AW} & =\text { abdominal width (at segment } \mathrm{V} \text { ) } \\
\mathrm{HL} & =\text { head length (at midline) } \\
\mathrm{HW} & =\text { head width (at temples) } \\
\mathrm{PRW} & =\text { prothoracic width (at posterior end) } \\
\mathrm{PTW} & =\text { pterothoracic width (at posterior end) } \\
\mathrm{TL} & =\text { total length (at midline) }
\end{aligned}
$$




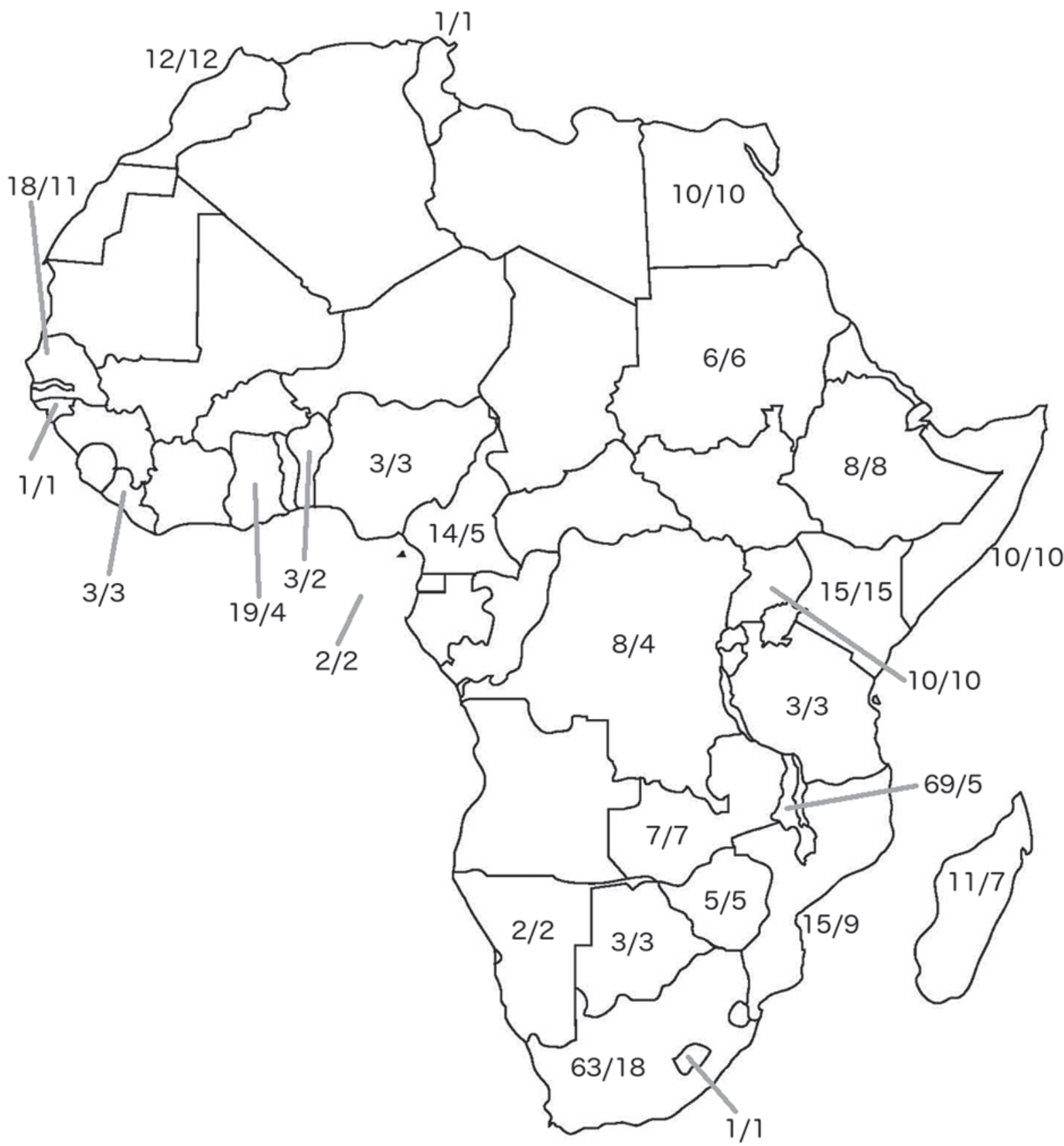

Fig. 1. Map of Africa, showing the number of species of chewing lice in the Brueelia complex reported from each country since Ledger (1980), including the records published herein. The first number represents the total number of records of host-louse associations reported for each country, disregarding that some records from different host species may refer to the same louse species. The second number represents the number of louse species identified to species level. Countries with no records of lice of the Brueelia complex since 1980 are unmarked. References to lice in the Brueelia complex known from each country can be found in the Appendix. Note that as no precise collection locality is given on older slides, records for Sudan and South Sudan are here presented together. The numbers ' $2 / 2$ ' in the Gulf of Guinea refer to São Tomé and Príncipe, which is not visible on the map. The islands of Réunion (France) and St. Helena (United Kingdom) are also not visible on the map; both have 1 record of a louse of the Brueelia complex in the time period, in both cases identified to species level. In addition to the records shown here, one species was recorded from "Northern Africa" and one from "Congo", with no more detailed locality given on the slide labels. 
The terminology of chaetotaxy and morphological structures follows Gustafsson \& Bush (2017), and includes:

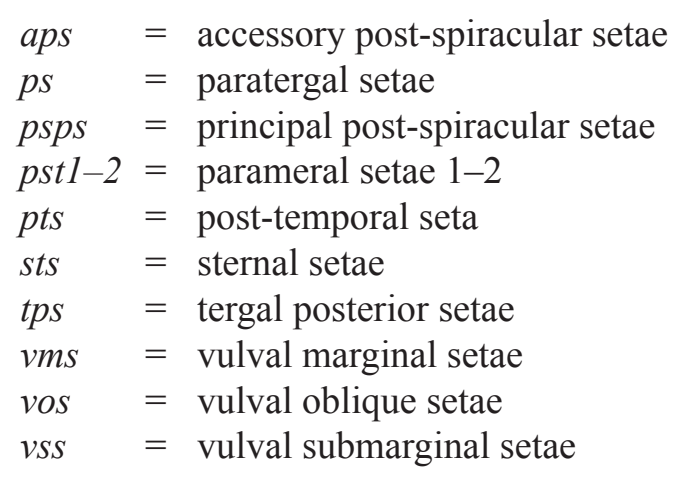

Counts of vos include the distal vos typically situated median to the vss. Setal characters are given in italics.

Host taxonomy follows Clements et al. (2018).

An index of specificity (IS) was calculated for all host families from which Brueelia are known in Africa, following Valim \& Weckstein (2013). Two estimates were calculated: one based only on the IS of identified species of Brueelia, and one on the IS of identified species of Brueelia plus unidentified species recorded from Africa (see Appendix). The latter IS was calculated under the assumption that all unidentified species listed as 'Brueelia sp.' in the Appendix are accurately assigned to genus, which is likely not the case for many specimens.

\section{Results}

The index of specificity was calculated for the genus Brueelia in Africa, following Valim \& Weckstein (2013); from this index, two estimates of the diversity of this genus in Africa were calculated (Table 1). In Table 1, an IS of 1 means that all species of Brueelia are host-specific within this host family. In host families for which IS $>1$, each host species is on average parasitized by more than one species of Brueelia; for instance, different host subspecies being parasitized by different species of Brueelia would give an IS $>1$. An IS $<1$ indicates that at least some Brueelia species parasitizing hosts in this family are not host-specific, but occur on more than one host species.

In almost all host families, the IS of Brueelia is 1, suggesting that Brueelia are generally host-specific. For nine host families, IS $<1$; however, in most of these cases, the species of Brueelia parasitizing hosts in this family have been poorly described, and some of these cases may represent misidentifications. Only one host family, Corvidae, has an IS $>1$.

Our two calculations of IS are based of different sets of reported taxa, and thus the two estimates of diversity of Brueelia are slightly different. However, both estimates suggest that well over 1000 species of Brueelia may occur in Africa. Only 30 species of Brueelia have been recorded from Africa since 1980 (Appendix). Using the IS estimate that includes unidentified specimens of Brueelia suggests that only $2.24 \%$ of the African diversity of Brueelia is currently known; using the more conservative IS estimate, and ignoring unidentified Brueelia, this number is $2.64 \%$. 


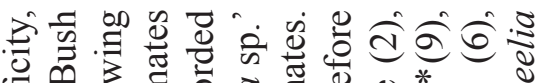

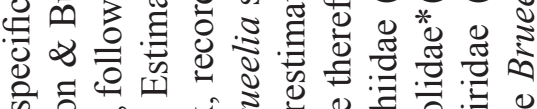

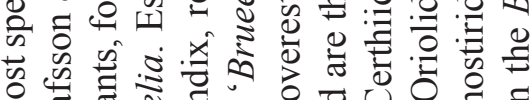

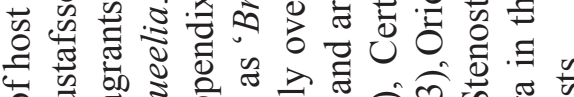

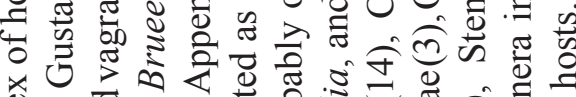

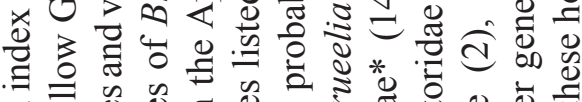

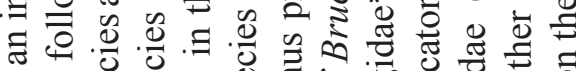
亏 ठ गे की की की

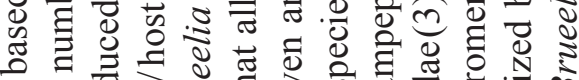

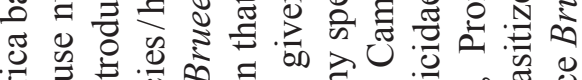

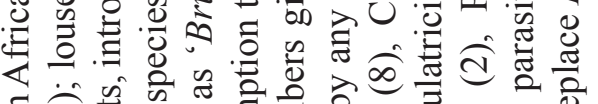

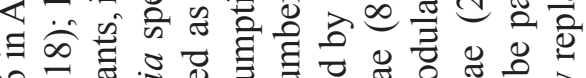

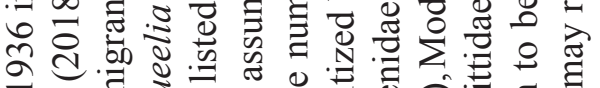

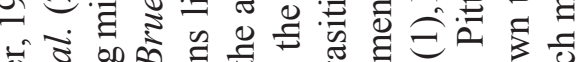

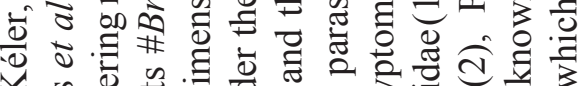

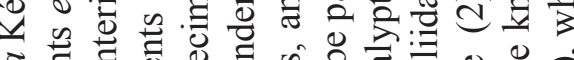

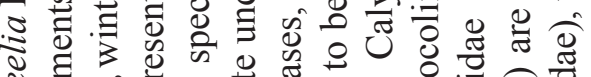
\&

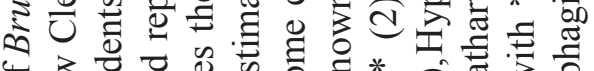

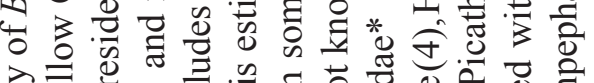

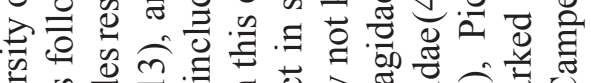
की

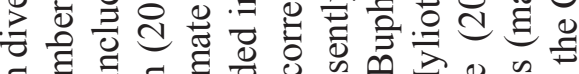

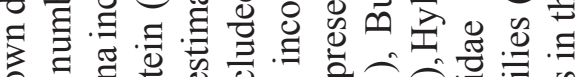

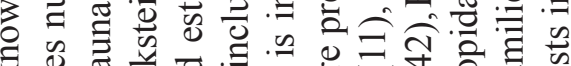

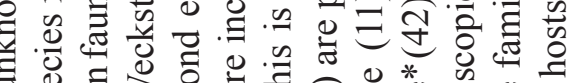
三 च की

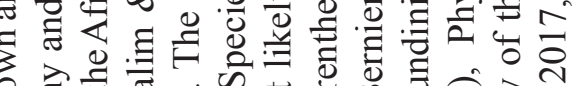

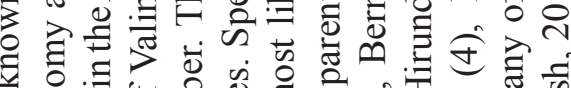

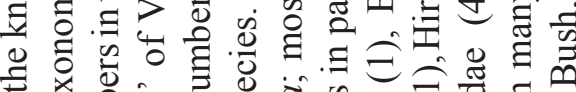

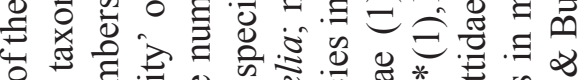

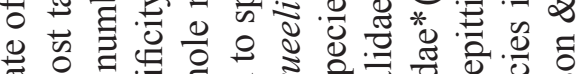

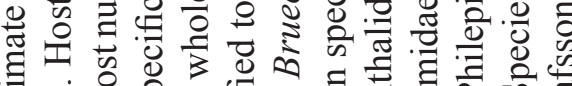

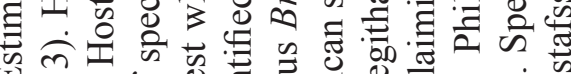

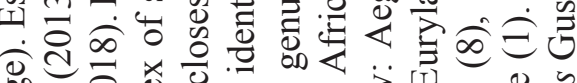

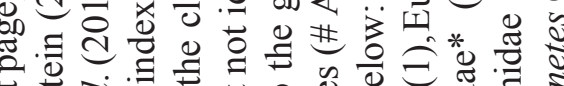

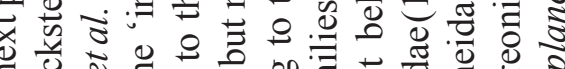

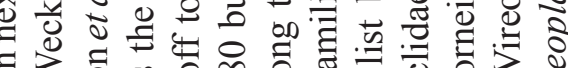
б

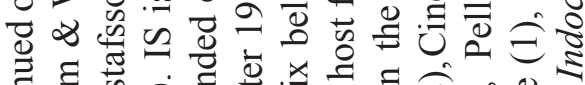

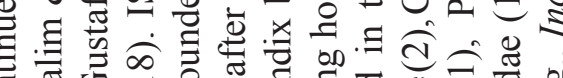

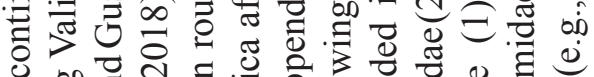

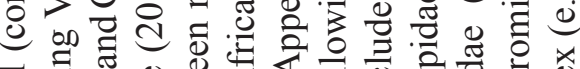
๘

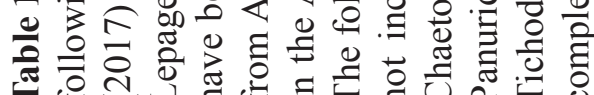

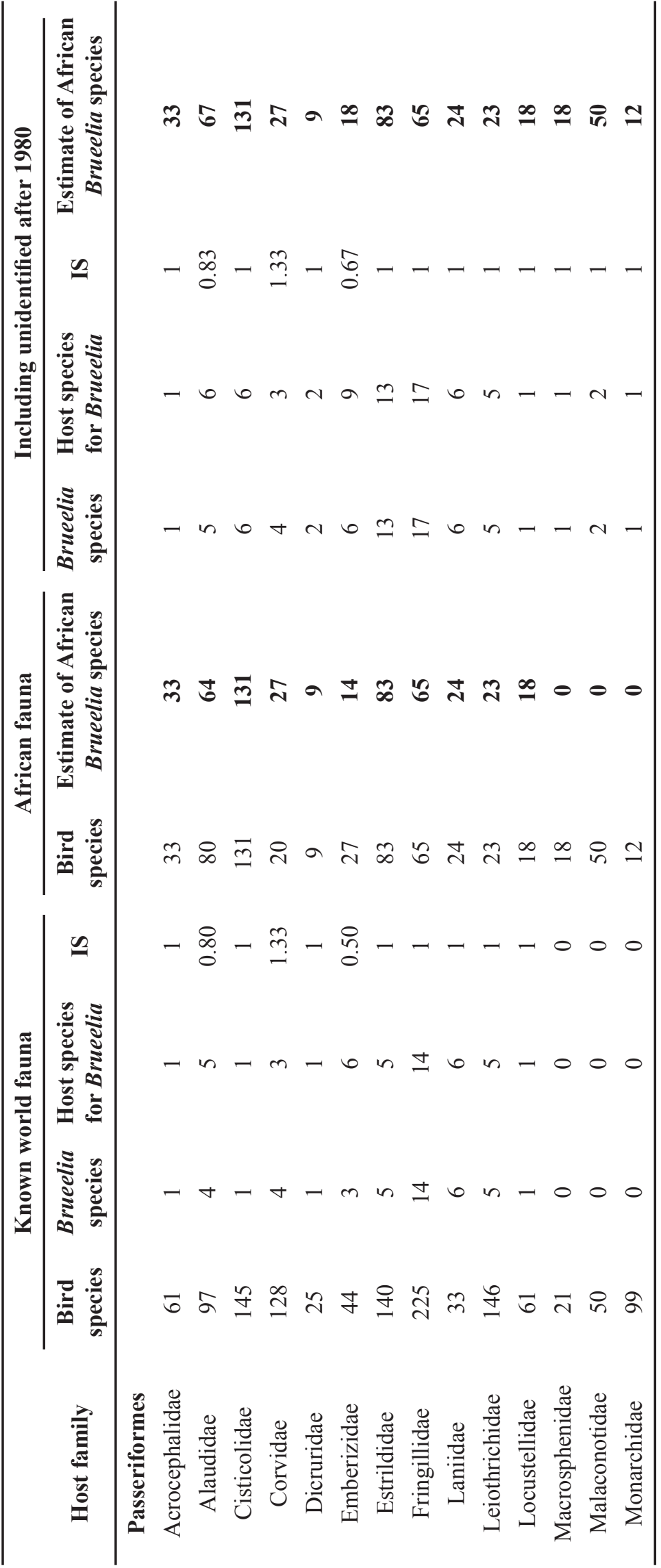




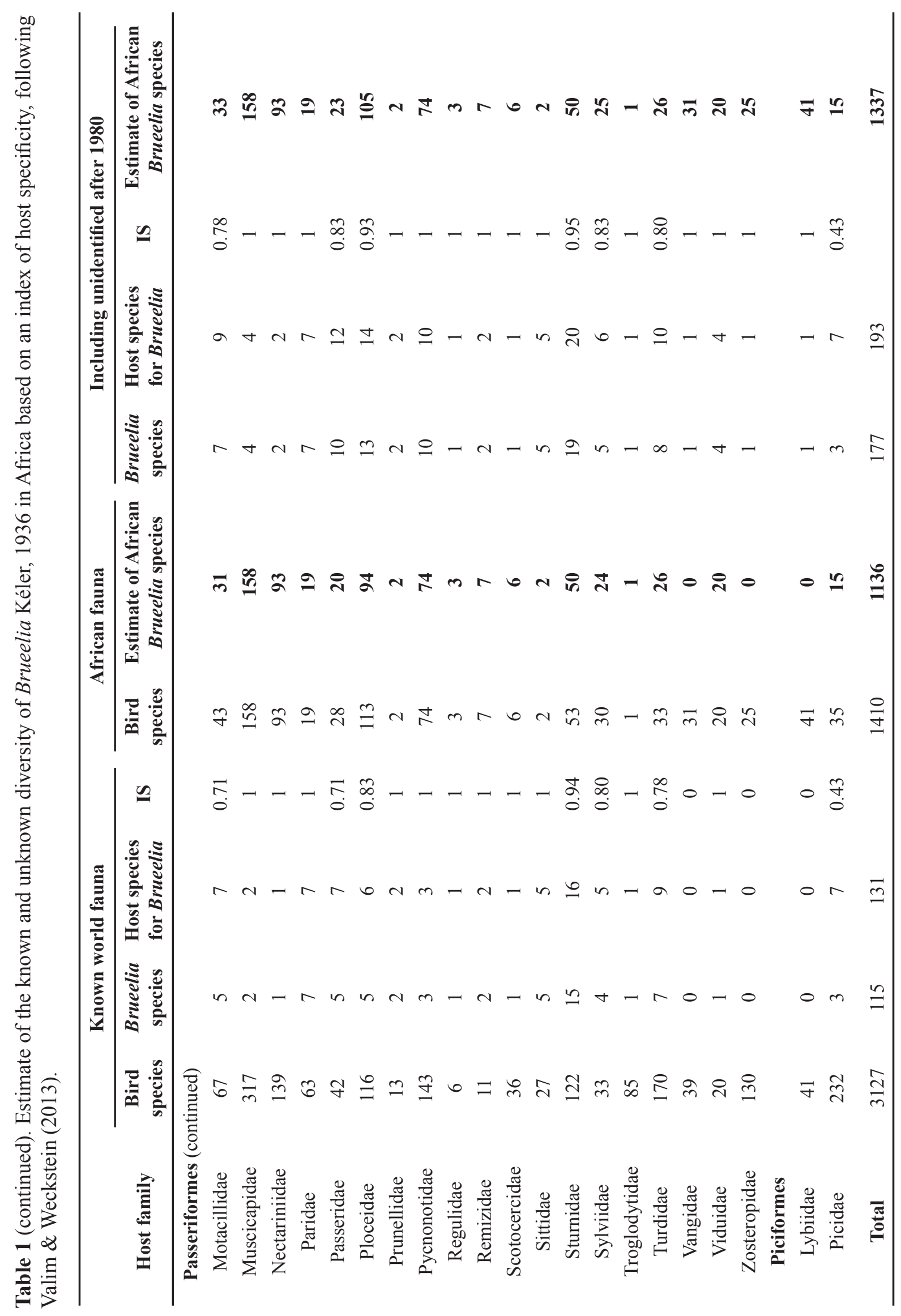




\author{
Order Phthiraptera Haeckel, 1896 \\ Suborder Ischnocera Kellogg, 1896 \\ Family Philopteridae Burmeister, 1838 \\ Brueelia complex sensu Gustafsson \& Bush 2017
}

Genus Brueelia Kéler, 1936

Philopterus Nitzsch, 1818: 288 partim.

Nirmus Nitzsch, 1818: 291 partim.

Degeeriella Neumann, 1906: 60 partim.

Brueelia Kéler, 1936: 257.

Painjunirmus Ansari, 1947: 285.

Allobrueelia Eichler, 1951: 36 partim.

Nigronirmus Złotorzycka, 1964: 248.

Spironirmus Złotorzycka, 1964: 261.

Serinirmus Soler Cruz et al., 1987: 244.

\title{
Type species
}

Brueelia rossittensis Kéler, 1936: 257 (=Nirmus brachythorax Giebel, 1874: 134) by original designation.

\section{Remarks}

Clay (1954) discussed the use of the post-spiracular sensillum in determining homology in the abdominal chaetotaxy of Ischnocera. She stated that in Brueelia, these sensilla are known from segments III-VII, whereas in all other groups of ischnoceran lice, they are never found posterior to segment V. Gustafsson \& Bush (2017) included these sensilla in their illustrations, but neglected to discuss their importance in the text. Based on our investigation of several hundred species of lice in the Brueelia complex, it seems that these sensilla occur on segments II-III only in the following genera: Brueelia, Teinomordeus Gustafsson \& Bush, 2017, Acronirmus Eichler, 1953 and Sychraella Gustafsson \& Bush, 2017. In all other genera of the Brueelia complex, these sensilla only occur on segments IV-V. However, they are typically very hard to see, especially in species with reduced tergopleurites.

Gustafsson \& Bush (2017) also neglected to explicitly state that it is the position of post-spiracular setae in relationship to this sensillum that determines whether they are psps or aps. Any setae positioned laterally to the sensillum are aps, whereas any setae situated immediately median to this sensillum are psps. Note that aps and psps on the first abdominal segment bearing post-spiracular setae (often segment V or VI in Brueelia) may be similar in length. Moreover, in some species of, e.g., Olivinirmus Złotorzycka, 1964 there may be more than one psps per side on some segments. To our knowledge, no species in the Brueelia complex has more than one aps per side on any segment.

Several of the species here belong to a group of pied Brueelia species found mainly on African hosts in the families Ploceidae, Estrildidae and Paridae. The only species of this group known from hosts outside Africa is Brueelia plocea (Lakshminarayana, 1968), from India. We have seen many additional species in this group, all from African hosts; however, suitable hosts in the same genera are found in South Asia. We here refer to this group as the "African pied Brueelia" group, to distinguish it from the New World ornatissima group, which have similar pigmentation patterns. This group comprises the following species: Brueelia plocea (Lakshminarayana, 1968); B. queleae Sychra \& Barlev in Sychra et al., 2010a; B. cantans Sychra in Sychra et al., 2010b; B. aguilarae Gustafsson \& Bush, 2017; B. mpumalangensis Gustafsson et al., 2018; B. semiscalaris sp. nov.; B. terspichore sp. nov.; B. sima sp. nov. 
The main characteristic of this group is the striking pigmentation pattern. This varies slightly between species, but typically includes having dark pigmentation on the anterior and posterior margins of sternites III-VI, the female tergopleurite IX $+\mathrm{X}$, along the lateral margins of the abdomen, around the distal section of femora I-III and on the subgenital plates. The dark areas are generally at least dark brown, but may appear black in some species; both sternal and subgenital plates typically have distinct translucent fenestrae in both sexes.

In the phylogeny of Bush et al. (2016), members of this group (e.g., Brueelia queleae and Brueelia sp. (=B. mpumalangensis) ex Melaniparus niger) were placed in different parts of the tree, suggesting that they do not form a natural group; however, these placements received no statistical support. Apart from pigmentation patterns, the morphological characters of this group are also very diverse, suggesting that the division of this group in the phylogeny of Bush et al. (2016) may be correct.

Nevertheless, for the purposes of identification and keying, we consider the 'African pied Brueelia' group a useful grouping to help sort out the vast diversity of species of Brueelia on African hosts. As more species of Brueelia from African hosts become known, the relationships of the species in this informal group may have to be revised, and the group may be found to be artificial. We provide a key to the described species in this group below.

\section{Key to the 'African pied Brueelia'}

Note that the dorsal abdominal setae in the original illustration of Brueelia plocea have been translocated to the ventral side (Lakshminarayana 1968). No dorsal setae are given in the original description (ibid.: table II), but multiple setae are illustrated on some segments; we interpret all setae on these segments except the sts as dorsal setae. The female of B. plocea is undescribed.

1. Male (n)

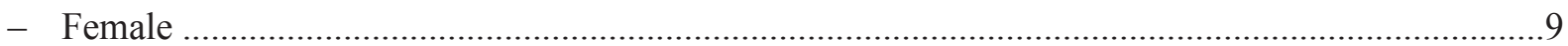

2. Accessory post-spiracular setae present on tergopleurite $\mathrm{V}$ (Fig. 9) .............................................

- Accessory post-spiracular setae absent on tergopleurite V (Fig. 23) ............................................6

3. Tergal posterior setae present on tergopleurites V-VI ..............................................................

- Tergal posterior setae absent on tergopleurites V-VI (Fig. 9) .......................................................

4. Frons rounded; aps present on tergopleurite IV

Brueelia queleae Sychra \& Barlev in Sychra et al., 2010a

- Frons flattened; aps absent on tergopleurite IV ......Brueelia cantans Sychra in Sychra et al., 2010b

5. Tergal posterior setae present on tergopleurite VII (Fig. 9); dark pigmentation of subgenital plate limited to anterior margin (Figs 9, 40) Brueelia semiscalaris sp. nov.

- Tergal posterior setae absent on tergopleurite VII; dark pigmentation of subgenital plate extensive along lateral margins, reaching distal end of subgenital plate

Brueelia aguilarae Gustafsson \& Bush, 2017

6. Preantennal head narrowly rounded ................................Brueelia plocea (Lakshminarayana, 1968)

- Preantennal head broad, frons either rounded or flattened (Fig. 25) .............................................7

7. Tergal posterior setae present on tergopleurite VI (Fig. 23) (absent in single examined specimen from E. p. delamerei); 2 ps on each side of abdominal segment IV (Fig. 23)

Brueelia terpsichore $\mathrm{sp}$. nov.

- Tergal posterior setae absent on tergopleurite VI (Fig. 30); 1 ps on each side of abdominal segment IV (Fig. 30) ...8 
8. Preantennal area roughly trapezoidal, with flattened frons (Fig. 32); tps present on tergopleurite VII (Fig. 30) Brueelia sima sp. nov.

- Preantennal area roughly semioval, with rounded frons; tps absent on tergopleurite VII Brueelia mpumalangensis Gustafsson et al., 2018

9. Frons rounded 10

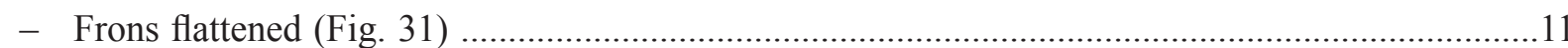

10. Subgenital plate largely translucent, with lateral areas of dark pigmentation clearly separated from anterior band of dark pigmentation .......Brueelia queleae Sychra \& Barlev in Sychra et al., 2010a

- Subgenital plate largely dark, with lateral and anterior sections of dark pigmentation fused Brueelia mpumalangensis Gustafsson et al., 2018

11. Pleural setae present on abdominal segment IV (Fig. 10)

- Pleural setae absent on abdominal segment IV (Fig. 31) Brueelia sima sp. nov.

12. Subgenital plate with largely dark pigmentation apart from a central more or less T-shaped translucent fenestra (sections of this fenestra may be interrupted as in Fig. 29)

- Subgenital plate largely translucent, but with central arched section of dark pigmentation connected to anterior band of dark pigmentation as in Figs 15, 39 Brueelia semiscalaris sp. nov.

13. Vulval margin with distinct median point Brueelia aguilarae Gustafsson \& Bush, 2017

- Vulval margin without distinct median point (Fig. 29)

14. Subgenital plate almost entirely dark, with translucent areas small and isolated from each other (Figs 29, 41)

Brueelia terpsichore sp. nov.

- Subgenital plate with clear central T-shaped translucent fenestrum

Brueelia cantans Sychra in Sychra et al., 2010b

\author{
Brueelia pofadderensis sp. nov. \\ urn:1sid:zoobank.org:act:374AAEBC-FB7D-455F-86A9-D3BC2360AD78
}

Figs $2-8,37-38$

\title{
Type host
}

Passer melanurus damarensis Reichenow, 1902 - Cape sparrow (Passeridae).

\section{Type locality}

Pofadder, Cape Province, South Africa.

\section{Other hosts}

Passer melanurus vicinus Clancey, 1958.

\section{Diagnosis}

Brueelia pofadderensis sp. nov. is a fairly typical species of Brueelia from hosts in the genus Passer Brisson, 1760. This informal group of Brueelia parasitizing Passer spp. is characterized by long, slender heads with convex lateral margins of the preantennal area, elongated parameres and the presence of aps but not psps on the male tergopleurite V. We have seen several undescribed species of this group (D.R. Gustafsson and S.E. Bush, in prep.), but the only described species in this group is Brueelia cyclothorax (Burmeister, 1838) (including N. subtilis Nitzsch in Giebel, 1874 and B. obligata Eichler, 1954). No adequate illustrations or descriptions of $B$. cyclothorax have been published, but partial illustrations 
were published by Eichler (1954) and Złotorzycka $(1964,1977)$. Note that the illustration in Eichler (1954) of the female abdomen mixes dorsal and ventral setae and characters on the same side. The frons in his illustrations are also incorrectly illustrated, as the hyaline margin has collapsed in his specimens.

Brueelia pofadderensis sp. nov. can be separated from B. cyclothorax by the following characters: abdominal segment III in both sexes without $p s$ in B. pofadderensis sp. nov. (Figs 2-3), but with $1 p s$ on each side in B. cyclothorax; male tergopleurite IV without aps in B. pofadderensis sp. nov. (Fig. 2), but with aps in B cyclothorax; antero-lateral corners of mesosomal lobes blunt in B. pofadderensis sp. nov. (Figs 5-6), but acute in B. cyclothorax; distal section of mesosome almost square-shaped in B. pofadderensis sp. nov. (Figs 5-6), but with more convergent lateral margins in B. cyclothorax; parameres more elongated in B. cyclothorax than in B. pofadderensis sp. nov. (Fig. 7).

\section{Etymology}

The specific epithet is derived from the type locality.

\section{Material examined}

Holotype

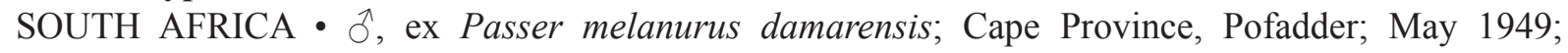
R. Meinertzhagen leg.; NHML 19050.

\section{Paratypes}

SOUTH AFRICA • $3 \hat{\jmath} \widehat{\jmath}$; same data as for holotype; NHML 19050.

UNKNOWN COUNTRY • 1 §, 1 \&, ex Passer melanurus demarensis; locality unknown; Mar. 1913; J. Waterston Collection, formerly South Africa Museum; British Museum; NHML 1930-232.

\section{Other material}

SOUTH AFRICA 1 ภ 1 , 1 , ex Passer melanurus vicinus; West Transvaal, Potchefstroom; May 1953; British Museum; NHML 1955-660 • 2 $\widehat{\jmath}, 1$ ㅇ, ex Passer melanurus vicinus; Transvaal, Ventersdorf; 12 Jul. 1954; H.E. Paterson leg.; British Museum; NHML 1955-660.

\section{Description}

Head slenderly rounded, dome-shaped (Fig. 4), lateral margins of preantennal area convex, frons slightly convex. Marginal carina narrow, with shallowly undulating median margins, displaced and widened at osculum. Ventral anterior plate large, with flat to shallowly concave anterior margin. Head chaetotaxy and pigmentation patterns as in Fig. 4; head sensilla and pts not visible in examined specimens. Preand postocular nodi of similar size. Marginal temporal carina slender, with undulating median margin. Gular plate broad, lanceolate. Thoracic and abdominal segments and pigmentation patterns as in Figs $2-3,37-38$.

\section{Male}

Thoracic and abdominal chaetotaxy as in Fig. 2; 1-2 tps on tergopleurite VI. Basal apodeme broad, with shallowly concave lateral margins (Fig. 5). Proximal mesosome broadly trapezoidal, widening slightly distally (Fig. 6). Mesosomal lobes wide, angular, with extensive rugose area along distal margin. Gonopore oval, slightly longer than wide. Penile arms reach beyond distal margin of mesosome. Parameres slender, elongated distally (Fig. 7); pst $1-2$ as in Fig. 7. Measurements ex P. m. damarensis $(\mathrm{n}=5): \mathrm{TL}=1.30-1.40 ; \mathrm{HL}=0.34-0.35 ; \mathrm{HW}=0.26-0.27 ; \mathrm{PRW}=0.16-0.18 ; \mathrm{PTW}=0.27 ; \mathrm{AW}=$ $0.35-0.38$. Measurements ex P. m. vicinus $(\mathrm{n}=3)$ : $\mathrm{TL}=1.39-1.51 ; \mathrm{HL}=0.34-0.36 ; \mathrm{HW}=0.26-0.30$; $\mathrm{PRW}=0.16-0.19 ; \mathrm{PTW}=0.27-0.31 ; \mathrm{AW}=0.36-0.41$. 

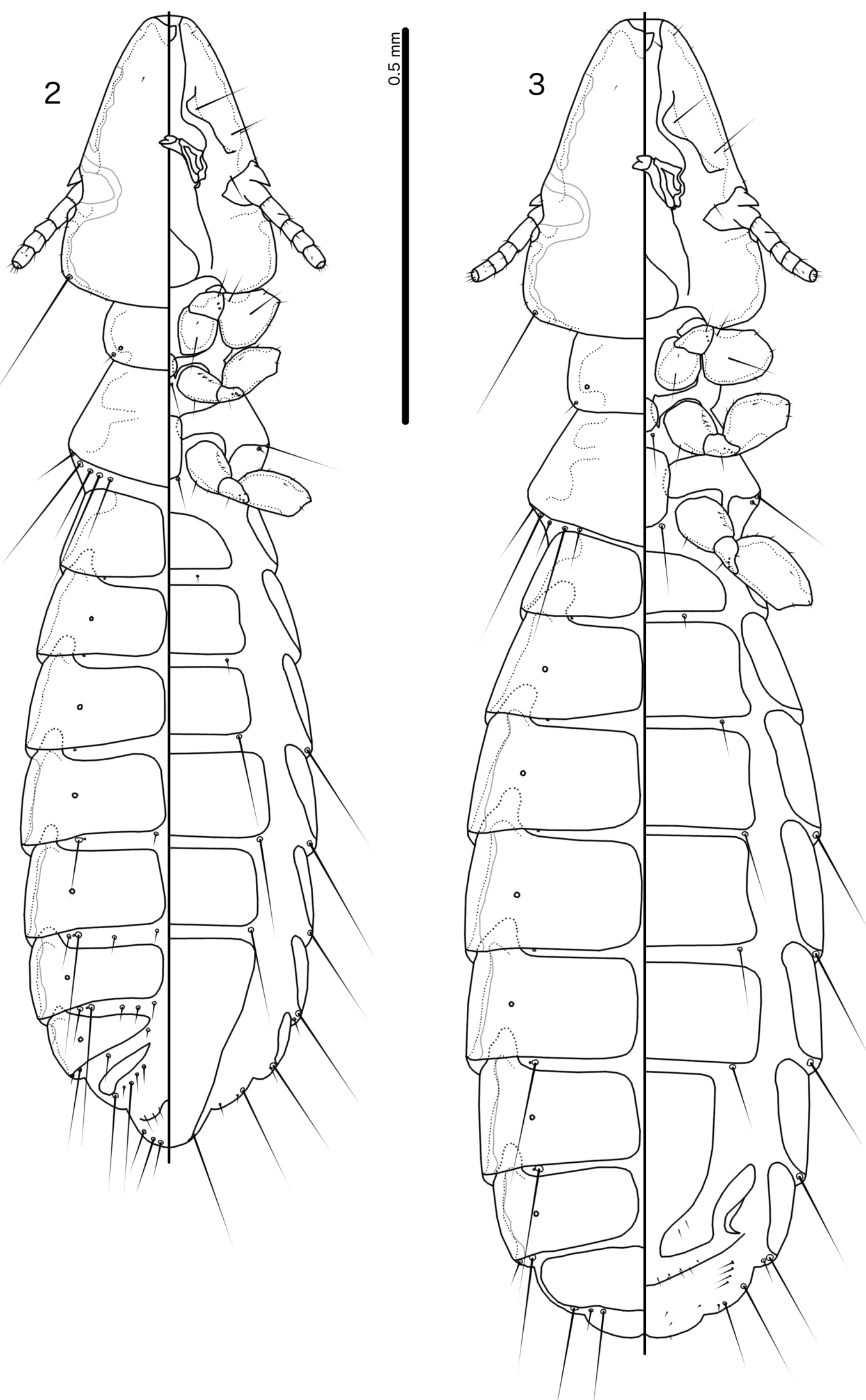

Figs 2-3. Brueelia pofadderensis sp. nov. ex Passer melanurus damarensis Reichenow, 1902. 2. Ô, holotype (NHML 19050), habitus, dorsal and ventral views. 3. + , habitus, dorsal and ventral views. 


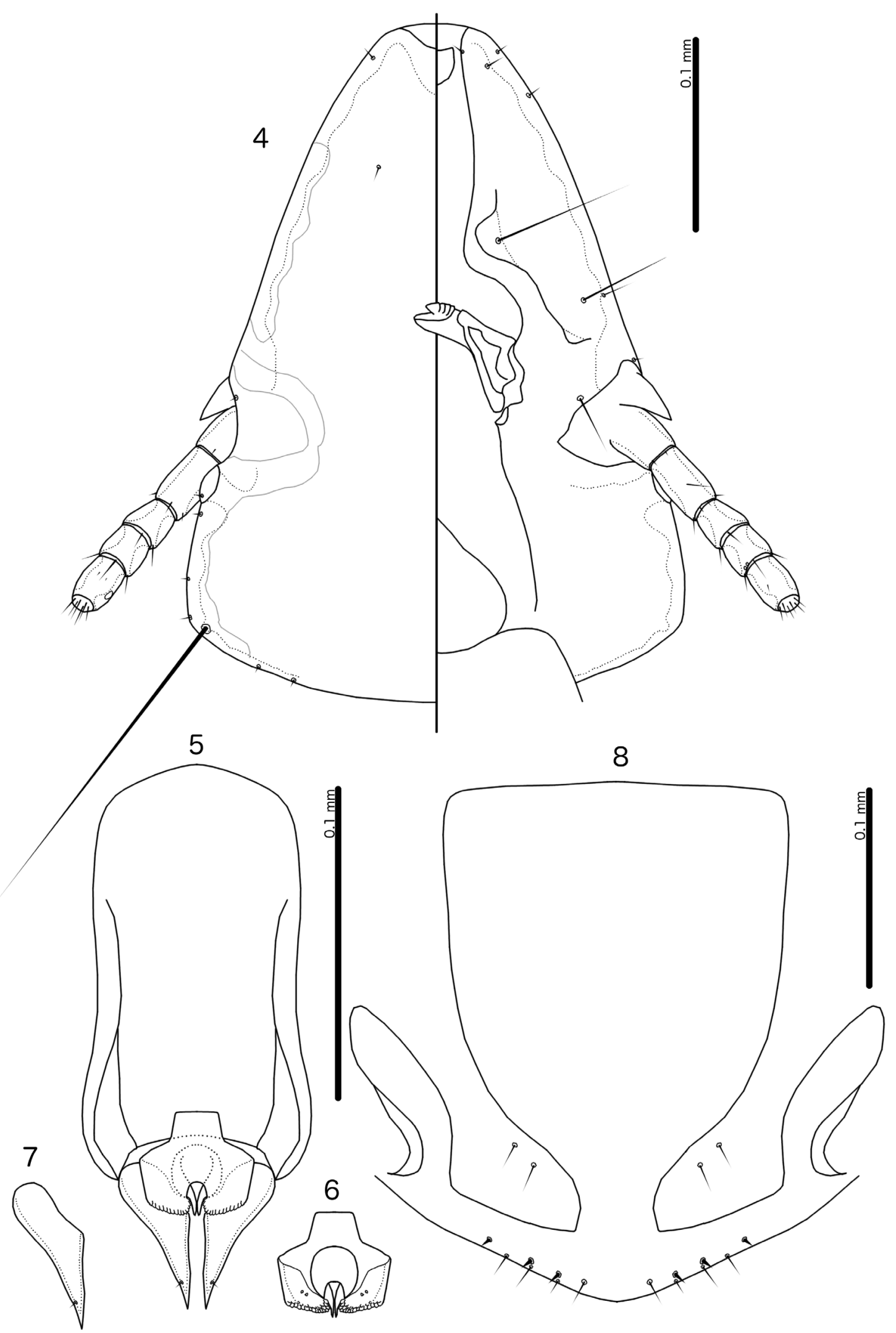

Figs 4-8. Brueelia pofadderensis sp. nov. ex Passer melanurus damarensis Reichenow, 1902. 4-7. §̂, holotype (NHML 19050). 4. Head, dorsal and ventral views. 5. Genitalia, dorsal view. 6. Mesosome, ventral view. 7. Paramere, dorsal view. 8. , subgenital plate and vulval margin, ventral view. 


\section{Female}

Thoracic and abdominal chaetotaxy as in Fig. 3. Subgenital plate rounded trapezoidal, with moderately wide connection to cross piece (Fig. 8). Vulval margin convergent to rounded median point, in specimen from type host subspecies with 2-3 short, slender vms and 3 short, thorn-like vss on each side; 3 short, slender vos on each side of subgenital plate; distal 1 vos median to vss. In material from P. m. vicinus, with 4 short, slender vms and 3-5 short, thorn-like vss on each side of vulval margin, and 2-3 short, slender vos on each side of subgenital plate, with distal 1 vos situated median to vss. Measurements ex P. $m$. damarensis $(\mathrm{n}=1): \mathrm{TL}=1.66 ; \mathrm{HL}=0.40 ; \mathrm{HW}=0.30 ; \mathrm{PRW}=0.20 ; \mathrm{PTW}=0.31 ; \mathrm{AW}=0.46$. Measurements ex P. m. vicinus $(\mathrm{n}=2)$ : $\mathrm{TL}=1.69-1.81 ; \mathrm{HL}=0.37-0.40 ; \mathrm{HW}=0.29-0.34 ; \mathrm{PRW}=$ $0.17-0.21 ; \mathrm{PTW}=0.29-0.33 ; \mathrm{AW}=0.40-0.47$.

\section{Remarks}

Specimens from the Transvaal host subspecies, Passer melanurus vicinus, differ from the specimens from the type host subspecies by having proportionately shorter and more rounded preantennal heads, in size and in the female genital chaetotaxy; the latter character may be different only due to the small number of specimens examined. The male genitalia and abdominal chaetotaxy are essentially similar between the two populations. We presently do not consider these differences substantial enough to warrant the erection of a new taxon for the specimens from Transvaal, but note that in some other cases, different host subspecies are parasitized by different species of Brueelia (D.R. Gustafsson and S.E. Bush, in prep.).

Brueelia semiscalaris sp. nov. urn:1sid:zoobank.org:act:FB13FA53-0431-4E3B-9050-04D1BDEA14C5

Figs 9-15, 39-40

\section{Type host}

Granatina granatina (Linnaeus, 1766) - violet-eared waxbill (Estrildidae).

\section{Type locality}

Mahalapye, Botswana.

\section{Diagnosis}

Brueelia semiscalaris sp. nov. belongs to the "African pied Brueelia" group (see above), but is the palest described member of this group. Within this group, B. semiscalaris sp. nov. is most similar to B. aguilarae Gustafsson \& Bush, 2017, with which it shares the following characters: head relatively slender (Fig. 11), with flattened frons and only slightly convex lateral margins of the preantennal area; mesosome with nearly parallel lateral margins and somewhat angular postero-lateral corners (Fig. 13); aps absent on male tergopleurite IV (Fig. 9); tps absent on male tergopleurites V-VI (Fig. 9); ps present on female abdominal segment IV (Fig. 10).

Brueelia semiscalaris sp. nov. can be separated from B. aguilarae by the following characters: tps present on male tergopleurite VII in B. semiscalaris sp. nov. (Fig. 9), but absent in B. aguilarae; parameres broad and roughly oval in B. semiscalaris sp. nov. (Fig. 14), but slender and elongated in B. aguilarae; proximal mesosome with convex lateral margins in B. aguilarae, but with concave lateral margins in B. semiscalaris sp. nov. (Fig. 13); gonopore about as long as wide and penile arms reaching beyond distal margin of mesosome in B. semiscalaris sp. nov. (Fig. 13), but gonopore very short and penile arms not reaching posterior margin of mesosome in $B$. aguilarae; female subgenital plate with central translucent, T-shaped fenestra in B. aguilarae, but with arched central dark pigmentation in B. semiscalaris sp. nov. 

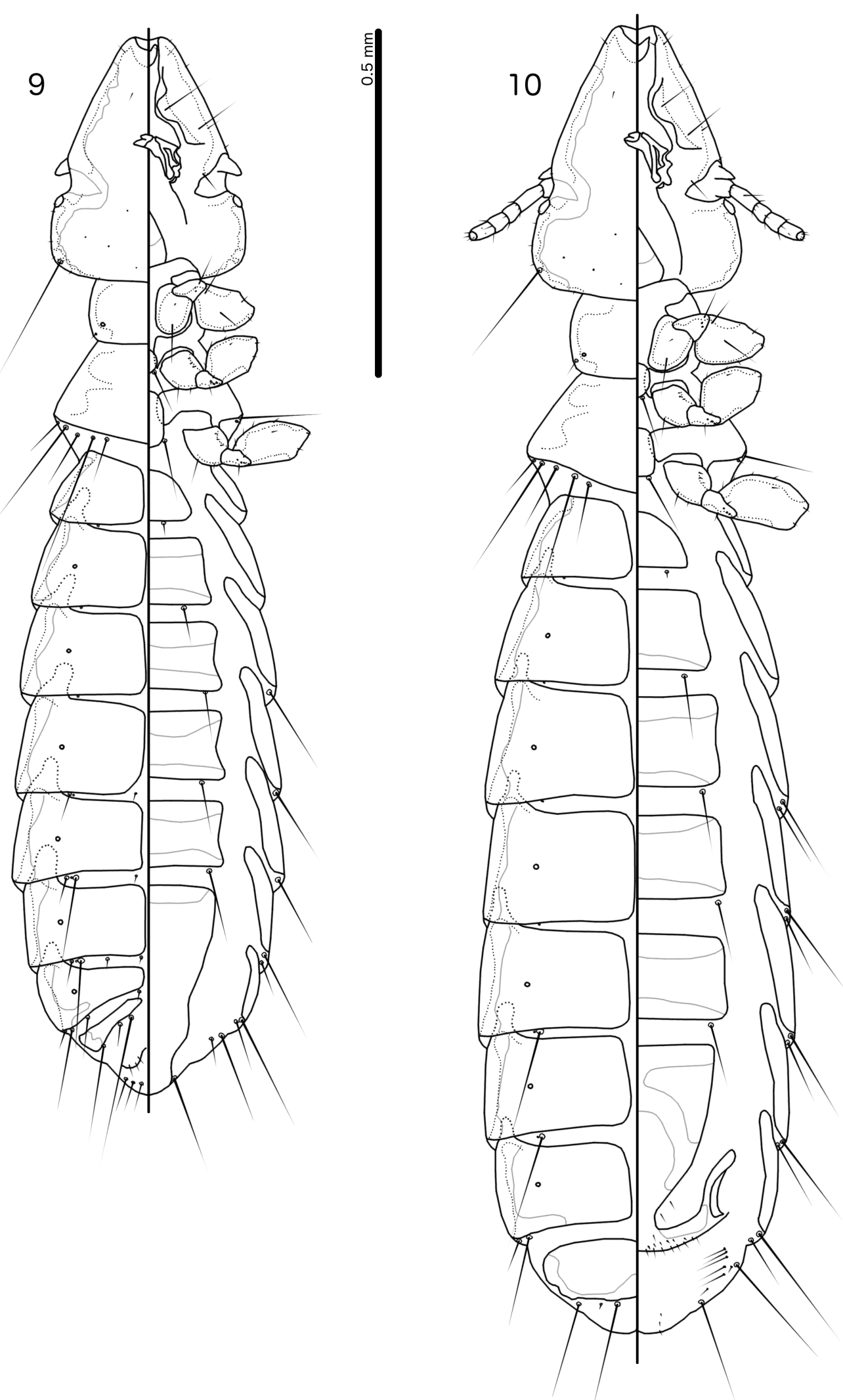

Figs 9-10. Brueelia semiscalaris sp. nov. ex Granatina granatina (Linnaeus, 1766). 9. §, holotype (NHML 1956-561), habitus, dorsal and ventral views. Antennae distorted in original, and not illustrated. 10. + , habitus, dorsal and ventral views. 


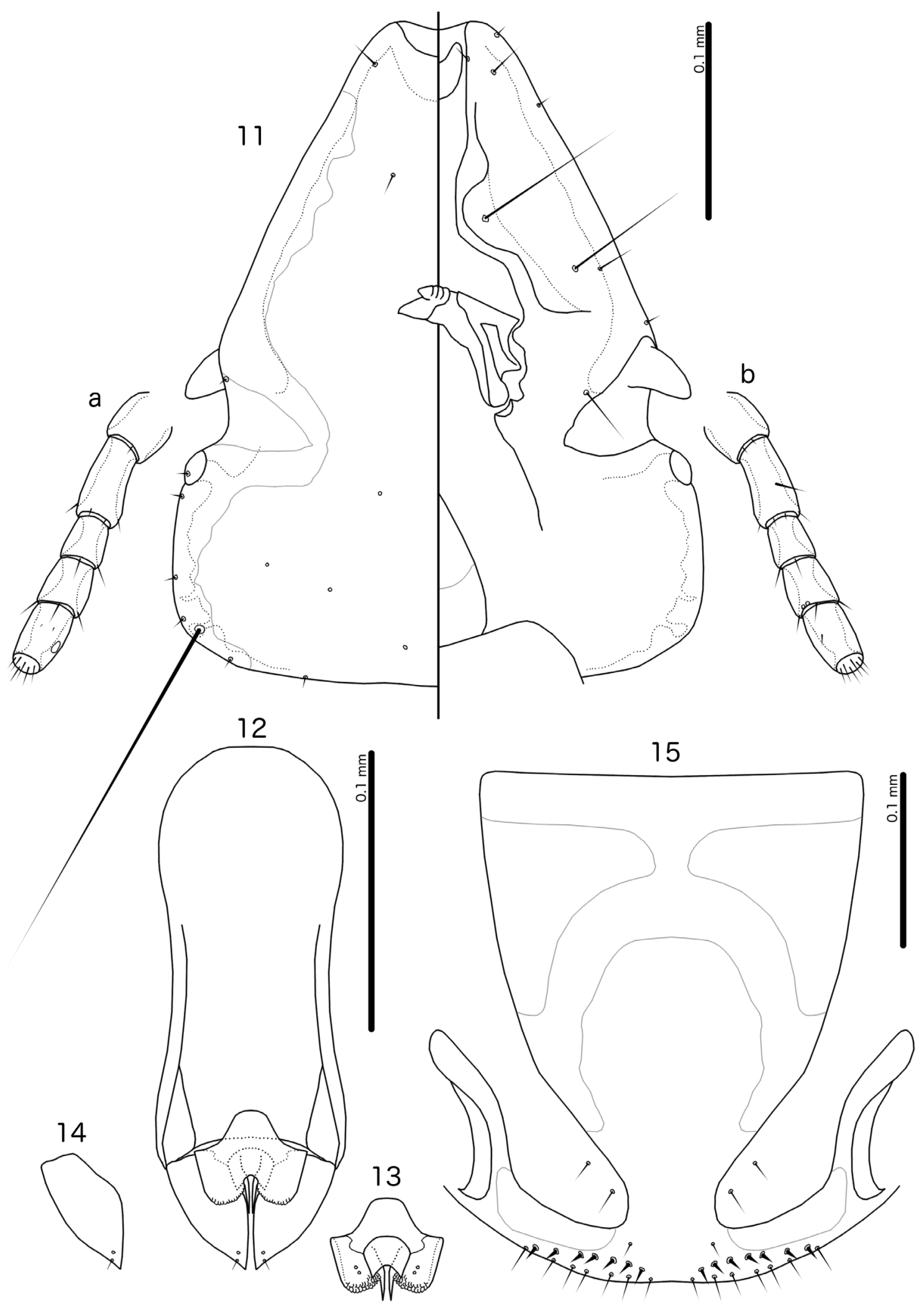

Figs 11-15. Brueelia semiscalaris sp. nov. ex Granatina granatina (Linnaeus, 1766). 11-14. $\overbrace{}^{\lambda}$, holotype (NHML 1956-561). 11. Head, dorsal and ventral views; $\mathbf{a}-\mathbf{b}$. Antennae from ${ }_{+}$, dorsal and ventral views. 12. Genitalia, dorsal view. 13. Mesosome, ventral view. 14. Paramere, dorsal view. 15. plate and vulval margin, ventral view. 
(Figs 15, 39); vulval margin with flattened median section in B. semiscalaris sp. nov. (Fig. 15), but with median point in B. aguilarae.

\section{Etymology}

The specific epithet is derived from the Latin 'semi' for 'partial, incomplete' and 'scalaris' for 'ladder', referring to the pigmentation pattern of the abdomen.

\section{Type material}

\section{Holotype}

BOTSWANA - O'; Bechuanaland (= Botswana), Mahalapye; 21 Dec. 1955; British Museum; NHML 1956-561.

\section{Paratype}

BOTSWANA • + ; same data as for holotype.

\section{Description}

Head rounded trapezoidal (Fig. 11), lateral margins of preantennal area slightly convex proximally and slightly concave distally, frons concave. Marginal carina moderate, deeply displaced and much widened at osculum, with almost even median margin. Ventral anterior plate large, with deeply concave anterior margin. Head chaetotaxy and pigmentation patterns as in Fig. 11. Preantennal nodi elongated. Preocular nodi much larger than postocular nodi. Marginal temporal carina moderate in width, with undulating median margin. Gular plate slender, lanceolate. Thoracic and abdominal segments and pigmentation patterns as in Figs 9-10, 39-40.

\section{Male}

Antennae folded ventrally in single examined male and cannot be illustrated accurately. Seemingly similar to female antennae (Fig. 11a-b) in shape and proportions, but paler. Thoracic and abdominal chaetotaxy as in Fig. 9; aps present on tergopleurite V; tps present on tergopleurite VII. Proximal basal plate almost entirely translucent, exact extent hard to ascertain; here illustrated tentatively (Fig. 12); slender with concave lateral margins. Proximal mesosome rounded trapezoidal, rather broad (Fig. 13). Mesosomal lobes with nearly parallel lateral margins and somewhat angular postero-lateral corners; rugose area extensive at distal end. Gonopore arched, about as wide as long. Penile arms long, reaching beyond distal margin of mesosome. Parameres broadly oval, not much elongated distally, with pst1-2 as in Fig. 14. Measurements $(\mathrm{n}=1)$ : $\mathrm{TL}=1.51 ; \mathrm{HL}=0.35 ; \mathrm{HW}=0.28 ; \mathrm{PRW}=0.18 ; \mathrm{PTW}=0.28$; $\mathrm{AW}=0.38$.

\section{Female}

Thoracic and abdominal chaetotaxy as in Fig. 10; ps present on abdominal segment IV. Subgenital plate rounded triangular, with broad connection to cross piece and unique pigmentation pattern (Fig. 15). Vulval margin flattened, median section somewhat concave, with 6-7 short, slender vms and 7-8 short, thorn-like $v s s$ on each side; 3 short, slender vos on each side of subgenital plate; distal 1 vos just anterior to vss. Measurements $(\mathrm{n}=1): \mathrm{TL}=1.91 ; \mathrm{HL}=0.40 ; \mathrm{HW}=0.31 ; \mathrm{PRW}=0.20 ; \mathrm{PTW}=0.32 ; \mathrm{AW}=0.46$.

\section{Brueelia bicurvata (Piaget, 1880)}

Figs 16-22

Nirmus bicurvatus Piaget, 1880: 159, pl. 13, fig. 8.

Degeeriella bicurvata - Harrison 1916: 109.

Brueelia bicurvata - Hopkins \& Clay 1952: 53. — Gustafsson \& Bush 2017: 38. 


\section{Type host}

Vidua paradisaea (Linnaeus, 1758) - long-tailed paradise whydah (Ploceidae).

\section{Type locality}

Original material from the Leiden Museum, but no type locality given by Piaget (1880).

\section{Material examined}

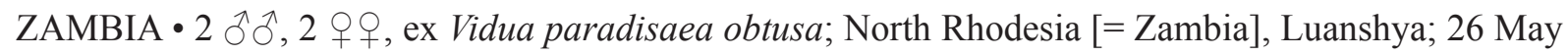
1955; British Museum; NHML 1955-486, ML/121.

\section{Description}

Head rounded trapezoidal (Fig. 18), lateral margins of preantennal area slightly convex proximally, but slightly concave distally, frons broadly flattened to slightly concave. Marginal carina slender, deeply displaced and much widened at osculum, and with median margin slightly undulating. Ventral anterior plate oblong, with rounded posterior margin. Head chaetotaxy and pigmentation pattern as in Fig. 18. Preantennal nodi elongated. Preocular nodi larger than postocular nodi. Marginal temporal carina slender, with slightly undulating median margin. Gular plate slenderly lanceolate. Thoracic and abdominal segments and pigmentation patterns as in Figs 16-17.

\section{Male}

Male subgenital plate does not reach terminal end of abdomen (Fig. 16). Thoracic and abdominal chaetotaxy as in Fig. 16. Basal apodeme broad, with concave lateral margins (Fig. 19). Proximal mesosome broad, convergent to median point, and with lateral extensions, making entire structure somewhat arrow-shaped (Fig. 20). Mesosomal lobes long and broad, with almost parallel lateral margins, rounded postero-lateral corners, and extensive rugose area along distal margin. Gonopore roughly semioval, about as long as wide. Penile arms long, reaching beyond distal margin of mesosome. Parameres long and broad, distal section elongated, with pst1-2 as in Fig. 21 . Measurements $(\mathrm{n}=2)$ : $\mathrm{TL}=1.48-$ $1.51 ; \mathrm{HL}=0.36 ; \mathrm{HW}=0.30 ; \mathrm{PRW}=0.20 ; \mathrm{PTW}=0.29-0.31 ; \mathrm{AW}=0.40-0.41$.

\section{Female}

Thoracic and abdominal chaetotaxy as in Fig. 17; psps present on tergopleurites IV-VII. Subgenital plate shaped as in Fig. 22, with broad connection to cross piece. Vulval margin somewhat convergent to median point, with 3-5 short, slender $v m s$ and 5-8 short, thorn-like $v s s$ on each side; 2-4 short, slender vos on each side of subgenital plate; distal 1 vos median to vss. Measurements $(\mathrm{n}=2)$ : $\mathrm{TL}=1.76-1.81$; $\mathrm{HL}=0.37-0.39 ; \mathrm{HW}=0.31-0.34 ; \mathrm{PRW}=0.20-0.21 ; \mathrm{PTW}=0.30-0.33 ; \mathrm{AW}=0.44-0.47$.

\section{Remarks}

The presence of psps on the female tergopleurites IV-V is unusual in Brueelia. No examples of females with psps on these segments were included in the list of variation in abdominal chaetotaxy of Brueelia published by Gustafsson \& Bush (2017: table 3). We know of no other species of Brueelia in which psps are present on the female tergopleurite IV, but psps are present on the female tergopleurite $\mathrm{V}$ in several species of Brueelia found on icterid hosts (Cicchino \& Castro 1996). Carriker (1963) illustrated setae on female tergopleurites III-VII in the position of $p s p s$ in B. mirabile Carriker, 1963, but did not illustrate any sts. It is therefore doubtful whether these setae represent psps or sts translocated to the dorsal side; we have not examined Carriker's material. In females of most genera in the Brueelia complex, psps are absent on tergopleurites IV-V, and the general absence of these setae in Brueelia (except in B. bicurvata) is unusual for the complex (Gustafsson \& Bush 2017: table 2).

A specimen of Brueelia from Vidua macroura was included in the phylogeny of Bush et al. (2016), but its placement as sister to the remaining Brueelia s. str. received no statistical support. As psps are 

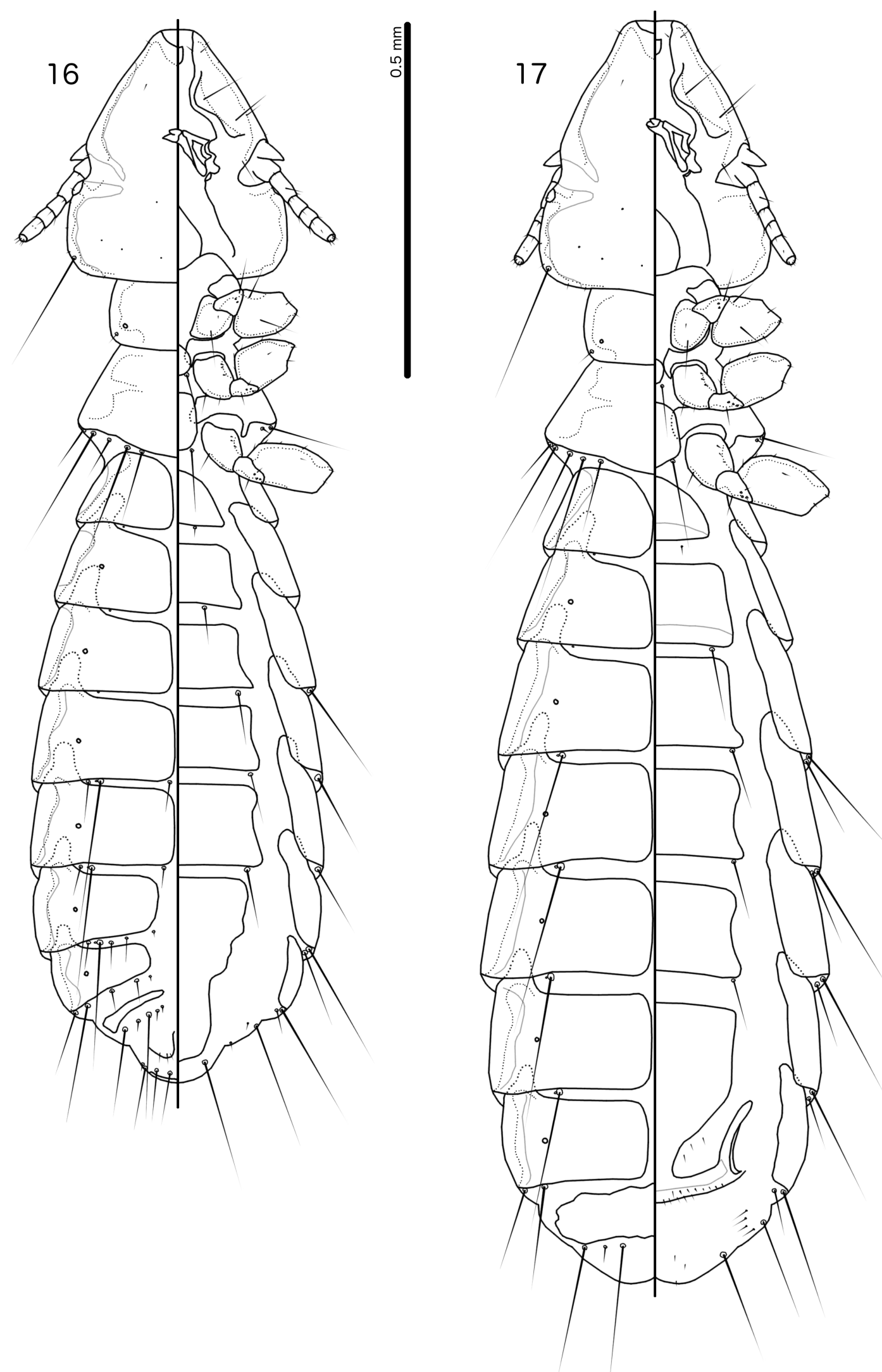

Figs 16-17. Brueelia bicurvata (Piaget, 1880) ex Vidua paradisaea (Linnaeus, 1758) (NHML 1955486, ML/121). 16. $\overbrace{}^{\Uparrow}$, habitus, dorsal and ventral views. 17. , , habitus, dorsal and ventral views. 


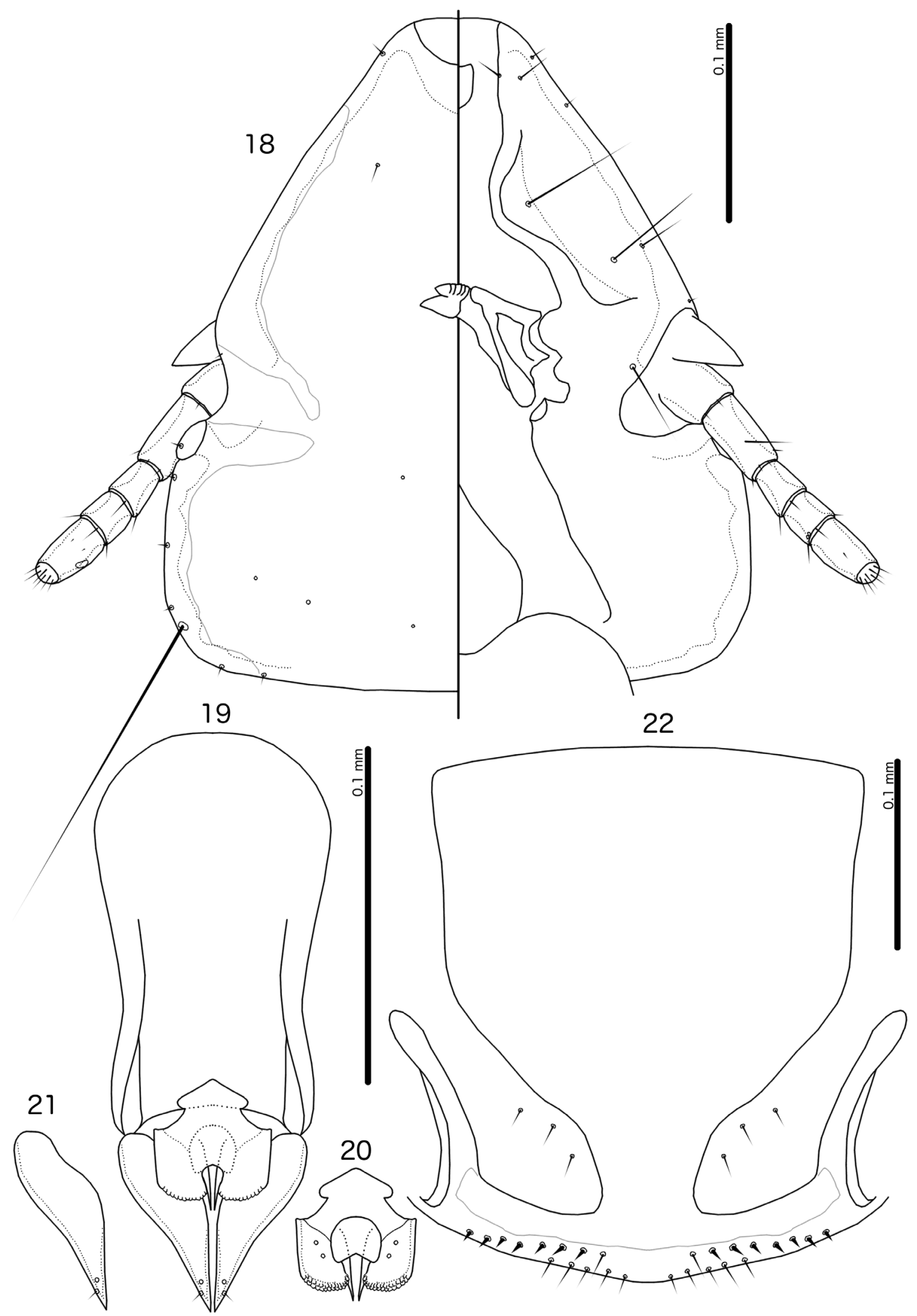

Figs 18-22. Brueelia bicurvata (Piaget, 1880) ex Vidua paradisaea (Linnaeus, 1758) (NHML 1955-

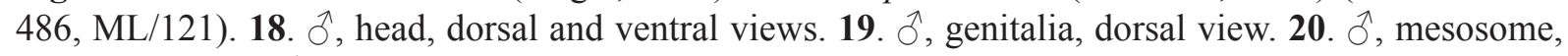
ventral view. 21. $\hat{\partial}$, paramere, dorsal view. 22. $q$, subgenital plate and vulval margin, ventral view. 
commonly found on female tergopleurites IV-V in many other genera of the Brueelia complex (see Gustafsson \& Bush 2017), it is possible that this represents the ancestral condition in the Brueelia complex, and that this placement as sister to the remaining Brueelia is correct.

Notably, these setae are present in both Formicaphagus Carriker, 1957 (see Price \& Clayton 1996) and Formicaricola Carriker, 1957 (see Price \& Clayton 1995), two of the genera most closely related to the Brueelia complex in the phylogeny of Bush et al. (2016). In the closest relative, Neopsittaconirmus Conci, 1942, the distribution of psps varies, e.g., present on III-VII in N. albus (Le Souëf \& Bullen, 1902) (Price \& Emerson 1978), but present only on IV-V in many species (Guimarães 1974) and only on IV in N. gracilis Guimarães, 1974 (see also Sychra 2005).

Brueelia terpsichore sp. nov.

urn:lsid:zoobank.org:act:A5296B28-CC4A-430B-928B-9A92B2AC5E2B

Figs 23-29, 41-42

\section{Type host}

Euplectes jacksoni (Sharpe, 1891) - Jackson's widowbird (Ploceidae).

\section{Type locality}

Kenya.

\section{Other host}

Euplectes progne delamerei (Shelley, 1903) - long-tailed widowbird.

\section{Diagnosis}

Brueelia terpsichore sp. nov. belongs to the informal 'African pied Brueelia' group (see above). Within this group, B. terpsichore sp. nov. is not particularly similar to any species. The extensive dark pigmentation of the sternites and subgenital plates of both sexes, the abdominal chaetotaxy, and the head shape suggests that $B$. aguilarae may be the closest relative of $B$. terpsichore sp. nov. These two species can be separated by the following characters: tps present on male tergopleurites VI-VIII in B. terpsichore sp. nov. (Fig. 23), but absent in B. aguilarae; male abdominal segment IV with 2 ps on each side in B. terpsichore sp. nov. (Fig. 23), but with 1 ps on each side in B. aguilarae; aps absent on male tergopleurite $\mathrm{V}$ in $B$. terpsichore sp. nov. (Fig. 23), but present in B. aguilarae; proximal mesosome broadly rounded in B. aguilarae, but trapezoidal in B. terpsichore sp. nov. (Fig. 27); translucent fenestra of female subgenital plate T-shaped in B. aguilarae, but divided into smaller, isolated fenestrae in B. terpsichore sp. nov. (Figs 29, 41; note that there is some variation between specimens in this species); vulval margin gently rounded in B. terpsichore sp. nov. (Fig. 29), but convergent to median point in B. aguilarae.

\section{Etymology}

The specific epithet is in honor of the Greek muse Terpsichore, goddess of dance; ultimately from the Greek 'terpo' for 'I delight' and 'khoros' for 'dance'. This refers to the peculiar lekking behaviour of the type host, which includes the construction of a small stage on which the male dances by jumping high into the air and singing to attract females (Andersson 1989, 1991).

\section{Material examined}

Holotype

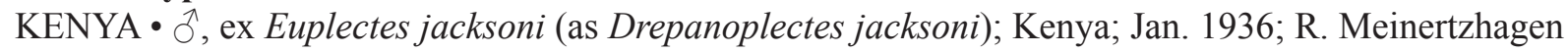
leg.; NHML 6084 (lower male on slide). 
Paratypes

KENYA • 2 ○ึ, 10 우; same data as for holotype; NHML 6081, 6082, 6084 (not lower male on slide), 6210.

\section{Other material}

KENYA 1 $\widehat{\jmath}, 1$, ex Euplectes progne delamerei (as Drepanoplectes progne delamerei); Kenya; Jan. 1936; R. Meinertzhagen leg.; NHML 6714.

\section{Description}

Head rounded trapezoidal (Fig. 25), lateral margins of preantennal area slightly convex or almost straight, frons broadly flattened. Marginal carina broad, deeply displaced and much widened at osculum, with undulating median margin. Ventral anterior plate not visible. Head chaetotaxy and pigmentation pattern as in Fig. 25. Preantennal nodi large, bulging. Pre- and postocular nodi large. Marginal temporal carina broad, with distinctly undulating median margin. Gular plate slender, lanceolate. Thoracic and abdominal segments and pigmentation patterns as in Figs 23-24, 41-42.

\section{Male}

Thoracic and abdominal chaetotaxy as in Fig. 23. Anterior section of basal apodeme not pigmented and cannot be seen clearly in examined specimens; illustration here is approximate (Fig. 26). Proximal mesosome rounded trapezoidal, widening distally, with concave lateral margins (Fig. 27). Mesosomal lobes relatively slender, rounded distally, with rugose area limited to distal margin. Gonopore crescentshaped, slightly wider than long. Penile arms short, not reaching beyond distal margin of mesosome. Parameres elongated, tapering gently (Fig. 28); pst1-2 as in Fig. 28. Measurements ex Euplectes jacksoni $(\mathrm{n}=3)$ : $\mathrm{TL}=1.42-1.48 ; \mathrm{HL}=0.33-0.34 ; \mathrm{HW}=0.26-0.28 ; \mathrm{PRW}=0.19 ; \mathrm{PTW}=0.26-0.27$; $\mathrm{AW}=0.36-0.37$. Measurements ex E. progne delamerei $(\mathrm{n}=1): \mathrm{TL}=1.44 ; \mathrm{HL}=0.34 ; \mathrm{HW}=0.26$; $\mathrm{PRW}=0.19 ; \mathrm{PTW}=0.27 ; \mathrm{AW}=0.35$.

\section{Female}

Thoracic and abdominal chaetotaxy as in Fig. 24. Pigmentation pattern of subgenital plate differing slightly between specimens; two variants shown in Fig. 29 (separated by grey line), one with anterolateral fenestra connected to antero-median fenestra and one with these fenestrae unconnected. Anteromedian fenestra generally pale brown in pigmentation, may extend posteriorly to approach posteromedian fenestra (not shown). Exact shape of postero-lateral fenestrae and translucent lateral borders of distal subgenital plate also differ between specimens. Subgenital plate rounded triangular, with moderate connection to cross piece. Vulval margin gently rounded, with 3-5 short, slender vms and 4-6 short, thorn-like vss on each side; 2-3 short, slender vos on each side of subgenital plate; distal 1 vos median to vss. Material from both host species with same vulval chaetotaxy. Measurements ex Euplectes jacksoni $(\mathrm{n}=10): \mathrm{TL}=1.58-1.73(1.66) ; \mathrm{HL}=0.36-0.38(0.37) ; \mathrm{HW}=0.28-0.31(0.30) ; \mathrm{PRW}=0.19-0.22$ $(0.21) ; \mathrm{PTW}=0.28-0.31(0.30) ; \mathrm{AW}=0.40-0.44(0.42)$. Measurements ex E. progne delamerei $(\mathrm{n}=1)$ : $\mathrm{TL}=1.73 ; \mathrm{HL}=0.37 ; \mathrm{HW}=0.30 ; \mathrm{PRW}=0.21 ; \mathrm{PTW}=0.31 ; \mathrm{AW}=0.40$.

\section{Remarks}

No significant differences have been found between specimens from the two host species, except that the single examined male from Euplectes progne delamerei lacks tps on tergopleurite VI. These are present in all specimens from the type host; however, the number varies between 1 and 2 . As only one male from $E$. p. delamerei was examined, we presently do not attach any significance to this difference, as the psps on this segment is also missing on one side. The absence of these setae may thus be due to individual variation. 

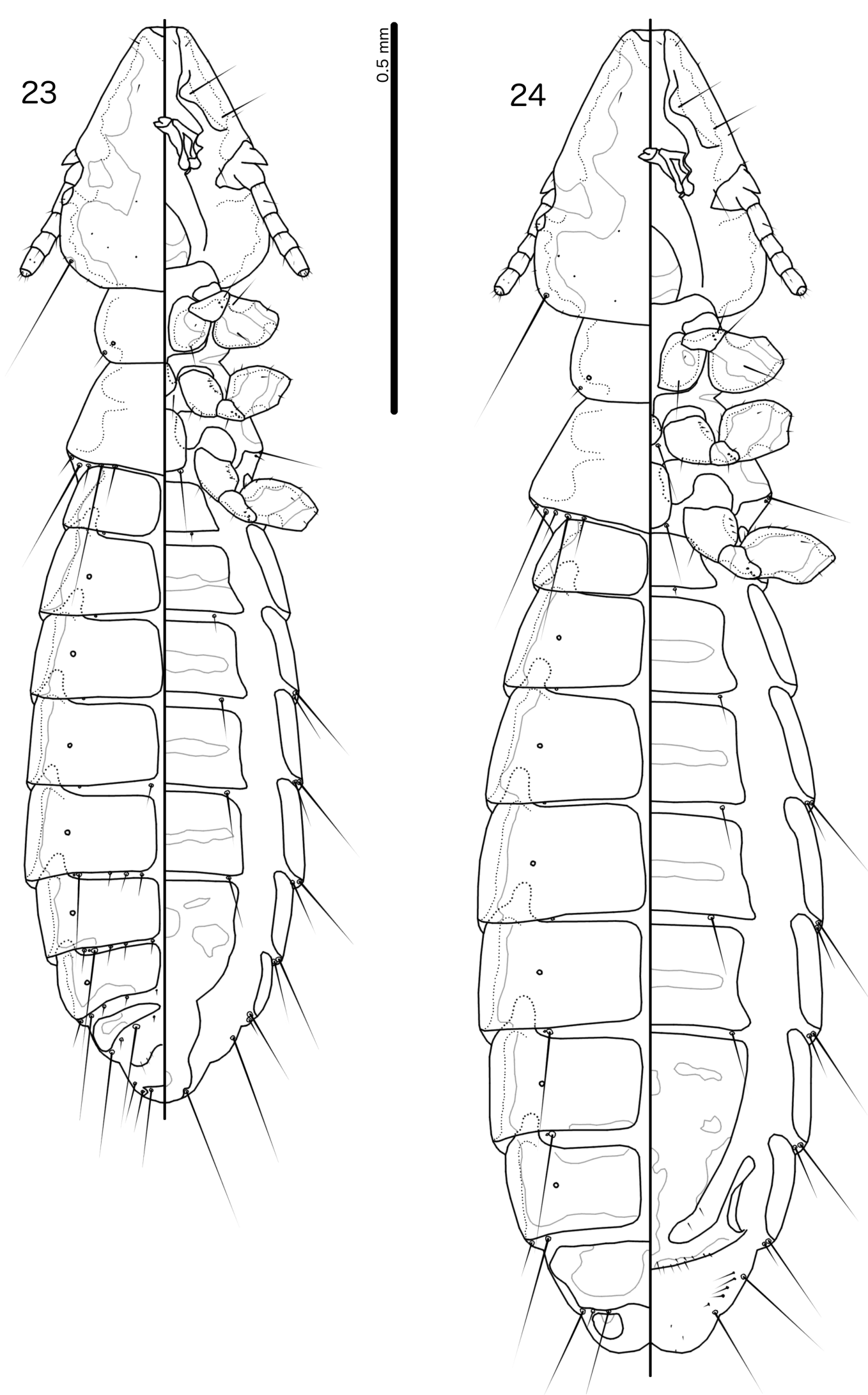

Figs 23-24. Brueelia terpsichore sp. nov. ex Euplectes jacksoni (Sharpe, 1891). 23. §, holotype (NHML 6084), habitus, dorsal and ventral views. 24. , habitus, dorsal and ventral views. 


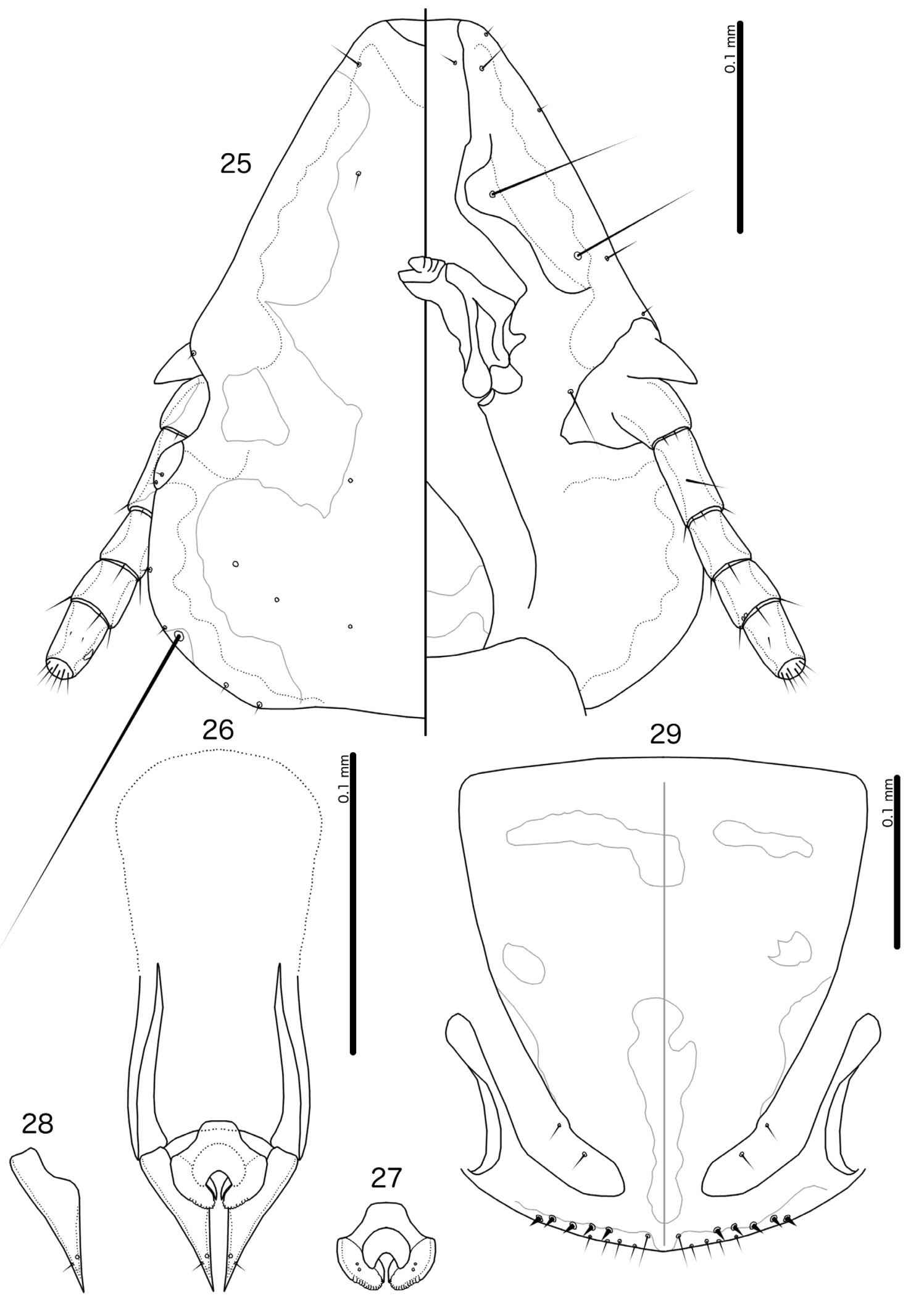

Figs 25-29. Brueelia terpsichore sp. nov. ex Euplectes jacksoni (Sharpe, 1891). 25-28. §ิ, holotype (NHML 6084). 25. Head, dorsal and ventral views. 26. Genitalia, dorsal view. 27. Mesosome, ventral view. 28. Paramere, dorsal view. 29. + , subgenital plate and vulval margin, ventral view. 


\title{
Brueelia sima sp. nov. urn:Isid:zoobank.org:act:3657A29B-5BDB-4E90-A0EC-AD665F787BC7
}

Figs 30-36, 43-44

\section{Type host}

Malimbus nitens (Gray, 1831) - blue-billed malimbe (Ploceidae).

\section{Type locality}

Batouri, Cameroon.

\section{Diagnosis}

Brueelia sima sp. nov. is part of the informal 'African pied Brueelia' group (see above). Within this group, $B$. sima sp. nov. does not appear to be particularly similar to any other species, but the head shape and proportions are most reminiscent of those in B. cantans Sychra in Sychra et al., 2010. These two species can be separated by the following characters: in B. cantans, aps and tps are present on male tergopleurites V-VI, but they are absent in B. sima sp. nov. (Fig. 30); multiple tps are present on male tergopleurite VII in $B$. cantans, but only a single tps is present on this segment in males of $B$. sima sp. nov. (Fig. 30); the mesosome has angular postero-lateral corners in B. cantans, but has rounded postero-lateral corners in B. sima sp. nov. (Fig. 34); parameres less elongated in B. sima sp. nov. (Fig. 35) than in B. cantans; the female subgenital plate with an anterior transversal fenestra, interrupted medianly, and with a large central fenestra separated from the anterior transversal fenestra in $B$. sima sp. nov. (Figs 36, 43), but with all these fenestrae continuous in B. cantans.

\section{Etymology}

The specific epithet is derived from the Latin 'simus' for 'snub-nosed', referring to the relatively short and broad preantennal area of this species.

\section{Type material}

\section{Holotype}

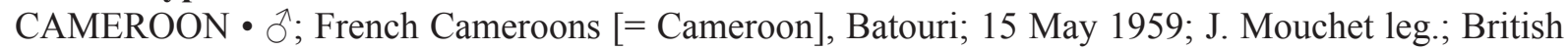
Museum; NHML 1960-295.

\author{
Paratype \\ CAMEROON • + ; same data as for holotype; NHML 1960-295.
}

\section{Description}

Head rounded trapezoidal (Fig. 32), lateral margins of preantennal area slightly convex, frons broadly flattened. Marginal carina broad, deeply displaced and much widened at osculum, and with undulating median margin. Ventral anterior plate broad, shield-shaped. Head chaetotaxy and pigmentation pattern as in Fig. 32. Preantennal nodi bulging, elongated. Preocular nodi much larger than postocular nodi. Marginal temporal carina broad, with distinctly undulating median margin. Gular plate broad, with concave antero-lateral margins. Thoracic and abdominal segments and pigmentation patterns as in Figs 30-31, 43-44.

\section{Male}

Thoracic and abdominal chaetotaxy as in Fig. 30. Basal apodeme broad, lateral margins concave (Fig. 33). Proximal mesosome roughly trapezoidal, widening slightly distally, and with anterior margin convergent to median point (Fig. 34). Mesosomal lobes broad, rounded distally, with extensive rugose area at distal end. Gonopore crescent-shaped, slightly wider than long. Penile arms short, not reaching 

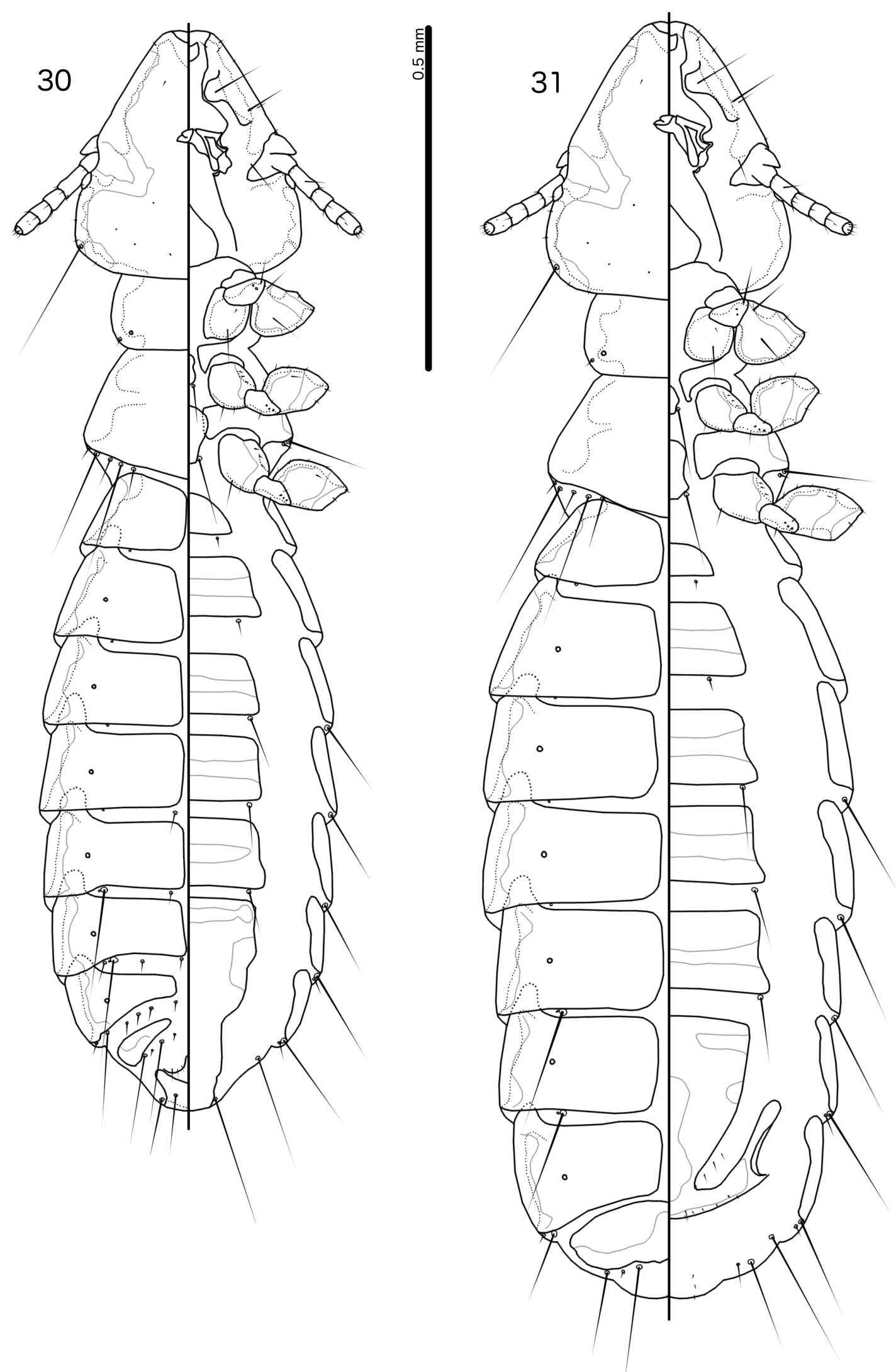

Figs 30-31. Brueelia sima sp. nov. ex Malimbus nitens (Gray, 1831). 30. §, holotype (NHML 1960295), habitus, dorsal and ventral views. 31. $q$, habitus, dorsal and ventral views. 


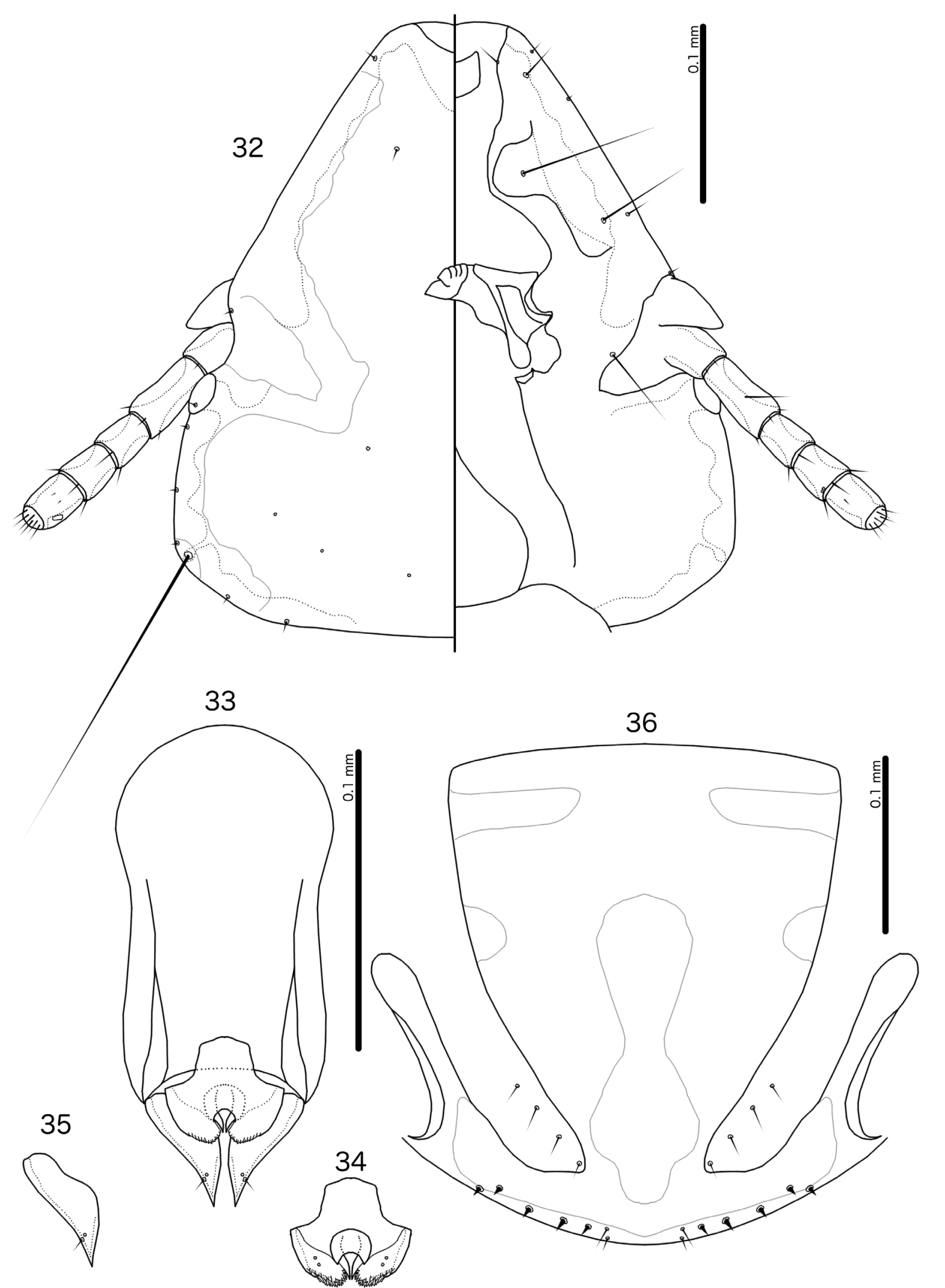

Figs 32-36. Brueelia sima sp. nov. ex Malimbus nitens (Gray, 1831). 32-35. §, holotype (NHML 1960-295). 32. Head, dorsal and ventral views. 33. Genitalia, dorsal view. 34. Mesosome, ventral view. 35. Paramere, dorsal view. 36. , subgenital plate and vulval margin, ventral view. 
beyond distal margin of mesosome. Parameres broad, not much elongated distally; pst1-2 as in Fig. 35. Measurements $(\mathrm{n}=1)$ : TL $=1.56 ; \mathrm{HL}=0.36 ; \mathrm{HW}=0.32 ; \mathrm{PRW}=0.23 ; \mathrm{PTW}=0.31 ; \mathrm{AW}=0.43$.

\section{Female}

Thoracic and abdominal chaetotaxy as in Fig. 31. Pigmentation pattern of subgenital plate as in Fig. 36; note that transition between brown and translucent areas of subgenital plate is gradual, and exact borders of translucent fenestra here approximate. Subgenital plate rounded triangular (Fig. 36), with broad connection to cross piece. Vulval margin gently rounded, with 1 short, slender vms and 4-5 short, thorn-like vss on each side; 3-6 short, slender vos on each side of subgenital plate; distal 1 vos median to vss. Measurements $(\mathrm{n}=1)$ : $\mathrm{TL}=1.80 ; \mathrm{HL}=0.39 ; \mathrm{HW}=0.35 ; \mathrm{PRW}=0.24 ; \mathrm{PTW}=0.35 ; \mathrm{AW}=0.53$.

\section{Remarks}

The abdomen of the single examined female is partially disrupted due to mounting; however, one side of every segment is undistorted. We have here illustrated the abdomen tentatively, based on the undistorted sides. However, the gonapophysal setae on segments VIII-X are absent on both sides of the specimen and are not illustrated here. These setae are present in all other species of the Brueelia complex, and when more specimens of $B$. sima sp. nov. are examined, it is likely that these setae will be found.

\section{Discussion}

The genetic data published by Bush et al. (2016), Light et al. (2016) and Takano et al. (2017, 2018) suggest that many of the Brueelia complex louse records from Africa represent distinct species, most of which appear to be host-specific. However, the vast majority of the species of chewing lice on African birds remain undescribed. We estimate that the potential Brueelia fauna of African passeriforms and piciforms comprises well over 1000 species (Table 1). The actual number of Brueelia recorded from Africa (including this report) is below 50 species. It is thus fair to say that the Brueelia fauna of Africa is almost entirely unknown, with less than $5 \%$ of the potential species described so far. These numbers are even worse when other genera in the Brueelia complex are included (data not shown).

For instance, 305 bird species that could potentially be parasitized by lice of the Brueelia complex (i.e., Passeriformes, Trogoniformes, Meropidae, Picidae) are listed as resident in South Africa by Sinclair et al. (2014). Chewing lice of the Brueelia complex have been reported from 51 of these potential host species since 1980, but only 18 of these reports are identified to species level (Appendix). Assuming that most of the lice of the Brueelia complex in South Africa are host-specific, and that most of the resident host species are infested with at least one louse species of the Brueelia complex, this suggests that the number of such species in South Africa may be underestimated by a factor of ten. The number of species of the Brueelia complex in all of Africa is most likely even more badly underestimated. The entirety of sub-Saharan West Africa has only 31 identified records of lice in the Brueelia complex (Appendix), but the region is home to over 560 species of potential host species (Borrow \& Demey 2014). Note that these numbers do not include migrants to these regions, and the number of potential host species is therefore much higher if non-resident bird species are included.

In addition, many passeriform birds are parasitized by more than one species of chewing lice of the Brueelia complex (Gustafsson \& Bush 2017). Moreover, there are indications that some host species are infested with different species of lice in the same genus in different parts of its range (e.g., Brueelia spp. on different subspecies of Plocepasser mahali (Smith, 1836); Gustafsson \& Bush, in prep.). In some cases, multiple Brueelia species occur on the same host even in the absence of different host subspecies (e.g., B. zohrae Ansari, 1956 and B. moreli Ansari, 1957, both on Ptilostomus afer (Linnaeus, 1766)). By contrast, some species of lice in the Brueelia complex occur on multiple host species (e.g., Balakrishnan \& Sorenson 2006; Bush et al. 2016), sometimes including host species from different families. Notably, four of the new genera described by Gustafsson \& Bush (2017) are presently known only from African 


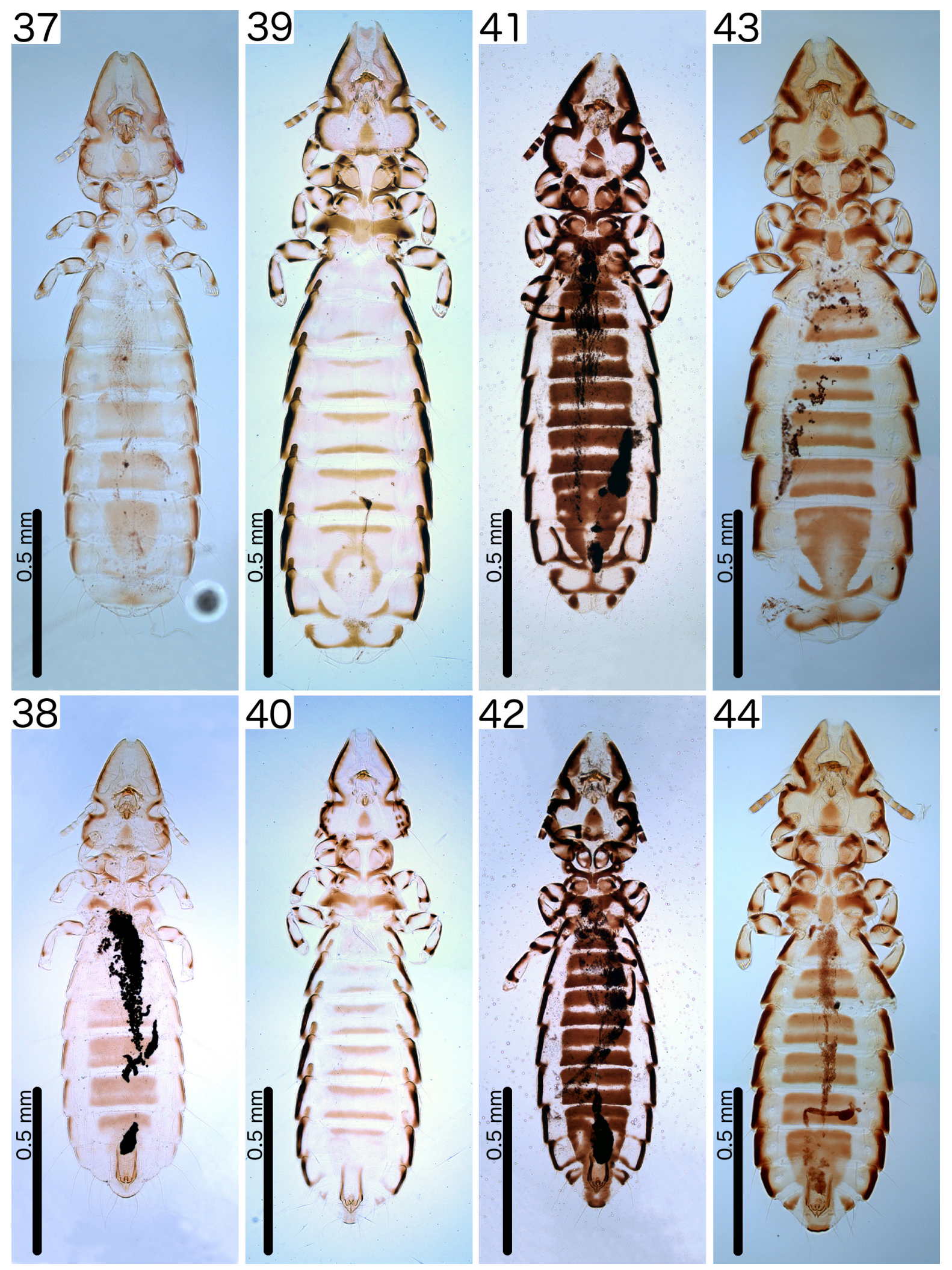

Figs 37-44. Habitus photos of the species of Brueelia described as new herein, showing overall pigmentation patterns. 37. B. pofadderensis sp. nov., +. 38. B. pofadderensis sp. nov., O. 39. B. semiscalaris

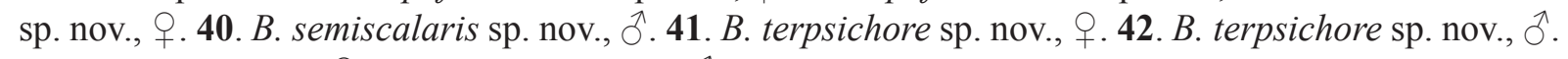
43. B. sima sp. nov.,, . 44. B. sima sp. nov., §̂. All photographs are to scale. 
endemic host groups. The undescribed diversity and host associations of African lice in the Brueelia complex may thus outweigh the known diversity significantly.

To a large extent, the lack of identifications to species level in these reports is due to the fact that very few chewing lice in the Brueelia complex have even been described from Africa. There is thus no framework of descriptions and illustrations with which to compare collected specimens. Here, we describe four new species of Brueelia from African hosts and redescribe one species. Three of these species belong to an apparently widely distributed informal group, characterised by their striking pigmentation patterns; a key to this informal group is provided. We hope that, together with those recently published by Gustafsson \& Bush $(2015,2017)$ and Gustafsson et al. (2018), the descriptions, illustrations and key characters presented here will make future identifications and descriptions of African species of Brueelia easier, and help us better understand the biodiversity and evolutionary history of the Brueelia complex.

\section{Acknowledgements}

Work was supported by the Introduction of Full-time High-level Talent Fund of the Guangdong Academy of Sciences grant no. 2018GDASCX-0809 and Guangdong Academy of Science (GDAS) Special Project of Science and Technology Development grants (2017GDASCX-0107 and 2018GDASCX-0107) to DRG, and the Guangdong Forestry Special Project grant no. 0877-16GZTP01D060 and the National Natural Science Foundation of China grant no. 31672265 to FZ. Paul Brown (NHML) prepared the loan of some specimens, for which we are grateful. We would also like to thank two anonymous reviewers for their help in making the published version of this manuscript better.

\section{References}

Andersson S. 1989. Sexual selection and cues for female choice in leks of Jackson's widowbird Euplectes jacksoni. Behavioral Ecology and Sociobiology 25: 403-410.

Andersson S. 1991. Bowers on the savanna: display courts and mate choice in a lekking widowbird. Behavioral Ecology 2: 210-218.

Ansari R.A.M. 1947. Mallophaga (Ischnocera) infesting birds in the Punjab (India). Proceedings of the National Institute of Science India 13: 253-303.

Ansari R.A.M. 1968. A review of the biting lice of the genus Sturnidoecus Elchler [sic], 1944 (Philopteridae: Mallophaga) found on the bird family Sturnidae (Passeriformes). Pakistani Journal of Health 17: 1-40.

Balakrishnan C.N. \& Sorenson M.D. 2006. Dispersal ecology versus host specialization as determinants of ectoparasite distribution in brood parasitic indigobirds and their estrildid finch hosts. Molecular Ecology 16: 217-229. https://doi.org/10.1111/j.1365-294x.2006.03142.x

Borrow N. \& Demey R. 2014. Birds of Western Africa. Christopher Helm, London.

Bush S.E., Weckstein J.D., Gustafsson D.R., Allen J., DiBlasi E., Shreve S.M., Boldt R., Skeen H.R. \& Johnson K.P. 2016. Unlocking the black box of feather louse diversity: A molecular phylogeny of the hyper-diverse genus Brueelia. Molecular Phylogenetics and Evolution 94: 737-751.

https://doi.org/10.1016/j.ympev.2015.09.015

Carriker Jr M.A. 1963. Neotropical Mallophaga (Insecta) miscellany no. 13. Revista Brasileira de Biologia 23: 293-316.

Cicchino A.C. \& Castro D.C. 1996. Revisión preliminar de las especies del género Brueelia Kéler, 1936 (Phthiraptera, Philopteridae) parásitas de Icterinae (Aves, Passeriformes, Fringillidae). Graellsia 52: 3-30. https://doi.org/10.3989/graellsia.1996.v52.i0.373 
Clay T. 1954. The post-spiracular seta and sensillus in the Mallophaga (Insecta). Annals and Magazine of Natural History, Series 127 (81): 716-718. https://doi.org/10.1080/00222935408651780

Clements J.F., Schulenberg T.S., Iliff M.J., Roberson D., Fredericks T.A., Sullivan B.L. \& Wood C.L. 2018. The eBird/Clements checklist of birds of the world: v. 2018.

Available from http://www.birds.cornell.edu/clementschecklist/download/ [accessed 29 Oct. 2018].

Eichler W. 1951. Die Federling die Drosseln. Bedeutung der Vogelwelt in Forschung und Praxis. Vorträge der I. Ornithologische Tagung der DDR am 21-22 Oktober 1950 in Leipzig 3: 29-47.

Eichler W. 1954. Deutsche Federlinge. I. Genus Brueelia. Nachrichten des Naturwissenschaftliche Museums Aschaffenburg 42: 59-66.

Giebel C. 1874. Insecta Epizoica. Otto Wigand, Leipzig.

Guimarães L.R. 1974. Ischnocera (Mallophaga) infesting parrots (Psittaciformes) I. Genera Neopsittaconirmus Conci, 1942, and Psittaconirmus Harrison, 1915. Arquivos de Zoologica 25: 121201.

Gustafsson D.R \& Bush S.E. 2015. Four new species of Brueelia Kéler, 1936 (Phthiraptera: Ischnocera: Philopteridae) from African songbirds (Passeriformes: Sturnidae and Laniidae). Zootaxa 4013: 503518. https://doi.org/10.11646/zootaxa.4013.4.2

Gustafsson D.R. \& Bush S.E. 2017. Morphological revision of the hyperdiverse Brueelia-complex (Insecta: Phthiraptera: Ischnocera: Philopteridae) with new taxa, checklists and generic key. Zootaxa 4313: 1-443. https://doi.org/10.11646/zootaxa.4313.1.1

Gustafsson D.R., Chu X., Bush S.E. \& Zou F. 2018. Ten new species of Brueelia Kéler, 1936 (Phthiraptera: Ischnocera: Philopteridae) from nuthatches (Aves: Passeriformes: Sittidae), tits and chickadees (Paridae), and goldcrests (Regulidae). Acta Parasitologica 63: 527-557. https://doi.org/10.1515/ap-2018-0063

Harrison L. 1916. The genera and species of Mallophaga. Parasitology 9: 1-156.

Hopkins G.H. \& Clay T. 1952. A Check List of the Genera and Species of Mallophaga. British Museum (Natural History), London.

Johnson K.P., Adams R.J. \& Clayton D.H. 2002. The phylogeny of the louse genus Brueelia does not reflect host phylogeny. Biological Journal of the Linnean Society 77: 233-247.

https://doi.org/10.1046/j.1095-8312.2002.00107.x

Kéler S. von 1936. Über einige Mallophagen aus Rossitten. Arbeiten in morphologische und taxonomische Entomologie von Berlin-Dahlem 3: 256-264.

Lakshminarayana K.V. 1968. Mallophaga Indica. II. A new species of Philopteridae on Ploceus philippinus burmannicus Ticehurst from India. Oriental Insects 2: 97-102.

Ledger J.A. 1980. The arthropod parasites of vertebrates in Africa south of the Sahara. Volume IV. Phthiraptera (Insecta). Publications of the South African Institute for Medical Research 56: 1-327.

Lepage D. 2018. Avibase - Bird checklists of the world: Africa. In: Web page Avibase - the world bird database. Available from

https://avibase.bsc-eoc.org/checklist.jsp?region=AFR\&list=clements [accessed 3 Dec. 2018].

Light J.E., Nessner C.E., Gustafsson D.R., Wise S.R. \& Voelker G. 2016. Remarkable levels of avian louse (Insecta: Phthiraptera) diversity in the Congo Basin. Zoologica Scripta 45: 538-551. https://doi.org/10.1111/zsc. 12170

Mey E. 2017. Neue Gattungen und Arten aus dem Brueelia-Komplex (Insecta, Phthiraptera, Ischnocera, Philopteridae s.1.) Rudolstädter naturhistorische Schriften 22: 85-215. 
Najer T., Sychra O., Literák, I., Procházka P., Capek M. \& Koubek P. 2012. Chewing lice (Phthiraptera) from wild birds in Senegal, with descriptions of three new species of the genera Brueelia and Philopteroides. Acta Parasitologica 57: 90-98. https://doi.org/10.2478/s11686-012-0005-x

Neumann L.G. 1906. Notes sur les Mallophages. Bulletin de la Société zoologique de France 31: 54-60.

Nitzsch C.L. 1818. Die Familien und Gattungen der Thierinsekten (Insecta Epizoica); als prodromus einer Naturgeschichte derselben. Magazin der Entomologie 3: 261-316.

Piaget E. 1880. Les Pédiculines. Essai Monographique. Two volumes. E.J. Brill, Leiden.

Price R.D. \& Clayton D.H. 1995. Review of Formicaricola (Phthiraptera: Philopteridae) from ground antbirds (Passeriformes: Formicariidae). Annals of the Entomological Society of America 88: 718-721.

Price R.D. \& Clayton D.H. 1996. Revision of the chewing louse genus Formicaphagus (Phthiraptera: Philopteridae) from Neotropical antbirds and gnateaters (Aves: Passeriformes). Journal of the Kansas Entomological Society 69: 346-356.

Price R.D. \& Emerson K.C. 1978. The Neopsittaconirmus (Mallophaga: Philopteridae) from Cacatua (Aves: Psittaciformes). Pacific Insects 18: 33-36.

Sinclair I., Hockey P., Tarboton W. \& Ryan P. 2014. The Larger Illustrated Guide to Birds of Southern Africa. Third edition. Struik Nature, Cape Town.

Soler Cruz M.D., Benítez Rodríguez R., Florido-Navío A. \& Muñoz Parra S. 1987. Some Mallophaga (Brueeliinae) from birds of the family Fringillidae. Acta Parasitologica Polonica 31: 241-246.

Sychra O. 2005. Morphological variation of Neopsittaconirmus gracilis (Phthiraptera, Ischnocera) from budgerigar, Melopsittacus undulatus. Biologia (Bratislava) 60: 137-142.

Sychra O., Barlev E.M., Literák I., Capek M., Koubek P. \& Procházka P. 2010a. The chewing lice (Phthiraptera) of red-billed quelea (Quelea quelea) in Senegal, with a description of a new species. African Entomology 18: 17-22. https://doi.org/10.4001/003.018.0103

Sychra O., Literák I., Najer T., Capek M., Koubek P. \& Procházka P. 2010b. Chewing lice (Insecta: Phthiraptera) from estrildid finches (Aves: Passeriformes: Estrildidae) and louse-flies (Insecta: Diptera: Hippoboscidae) from birds in Senegal, with descriptions of three new species of the genus Brueelia. Zootaxa 2714: 59-68.

Takano O.M., Mitchell P.S., Gustafsson D.R., Adite A., Voelker G. \& Light J.E. 2017. An assessment of host associations, geographic distributions, and genetic diversity of avian chewing lice (Insects: Phthiraptera) from Benin. Journal of Parasitology 103: 152-160. https://doi.org/10.1645/16-137

Takano O.M., Voelker G., Gustafsson D.R. \& Light J.E. 2018. Molecular phylogeny and novel host associations of avian chewing lice (Insecta: Phthiraptera) from South Africa. Systematic Entomology. https://doi.org/10.1111/syen.12319

Tendeiro J. 1989. Nouvelle observations sur les genres Meropoecus Eichler 1940 et Splendoroffula Th. Clay et Menertzhagen [sic], 1941 (Mallophaga, Ischnocera). Garcia de Orta, Séries Zoologia 15: 99-104.

Tendeiro J. \& Mendes L.F. 1994. Sobre a fauna terrestre e ribeirinha de República Democrática de São Tomé e Príncipe. Malófagos. II. Espécies encontradas e notas adicionais sobre a fauna malofágica de São Tomé e Príncipe. Garcia de Orta, Séries Zoologia 20: 113-130.

Valim M.P. \& Weckstein J.D. 2013. A drop in the bucket of the megadiverse chewing louse genus Myrsidea (Phthiraptera, Amblycera, Menoponidae): ten new species from Amazonian Brazil. Folia Parasitologica 60: 377-400. https://doi.org/10.14411/fp.2013.040 
Williams N.S. 1981. The Brueelia (Mallophaga: Philopteridae) of the Meropidae (Aves: Coraciiformes). Journal of the Kansas Entomological Society 54: 510-518.

Złotorzycka J. 1964. Mallophaga parasitizing Passeriformes and Pici. II. Brueeliinae. Acta Parasitologica Polonica 12: 239-282.

Złotorzycka J. 1977. Wszoły - Mallophaga, Zeszyt 4. Nadrodzina Philopteroidea: rodzina Philopteridae. Klucze do Ozaczania Owasów Polski 15: 1-124.

Złotorzycka J., Madrzejewska M. \& Kopij G. 1999. A preliminary study on Mallophaga in South African birds. Polskie Pismo Entomologiczne 68: 9-21.

Manuscript received: 14 December 2018

Manuscript accepted: 11 February 2019

Published on: 19 March 2019

Topic editor: Gavin Broad

Desk editor: Danny Eibye-Jacobsen

Printed versions of all papers are also deposited in the libraries of the institutes that are members of the EJT consortium: Muséum national d'Histoire naturelle, Paris, France; Meise Botanic Garden, Belgium; Royal Museum for Central Africa, Tervuren, Belgium; Royal Belgian Institute of Natural Sciences, Brussels, Belgium; Natural History Museum of Denmark, Copenhagen, Denmark; Naturalis Biodiversity Center, Leiden, the Netherlands; Museo Nacional de Ciencias Naturales-CSIC, Madrid, Spain; Real Jardín Botánico de Madrid CSIC, Spain; Zoological Research Museum Alexander Koenig, Bonn, Germany. 


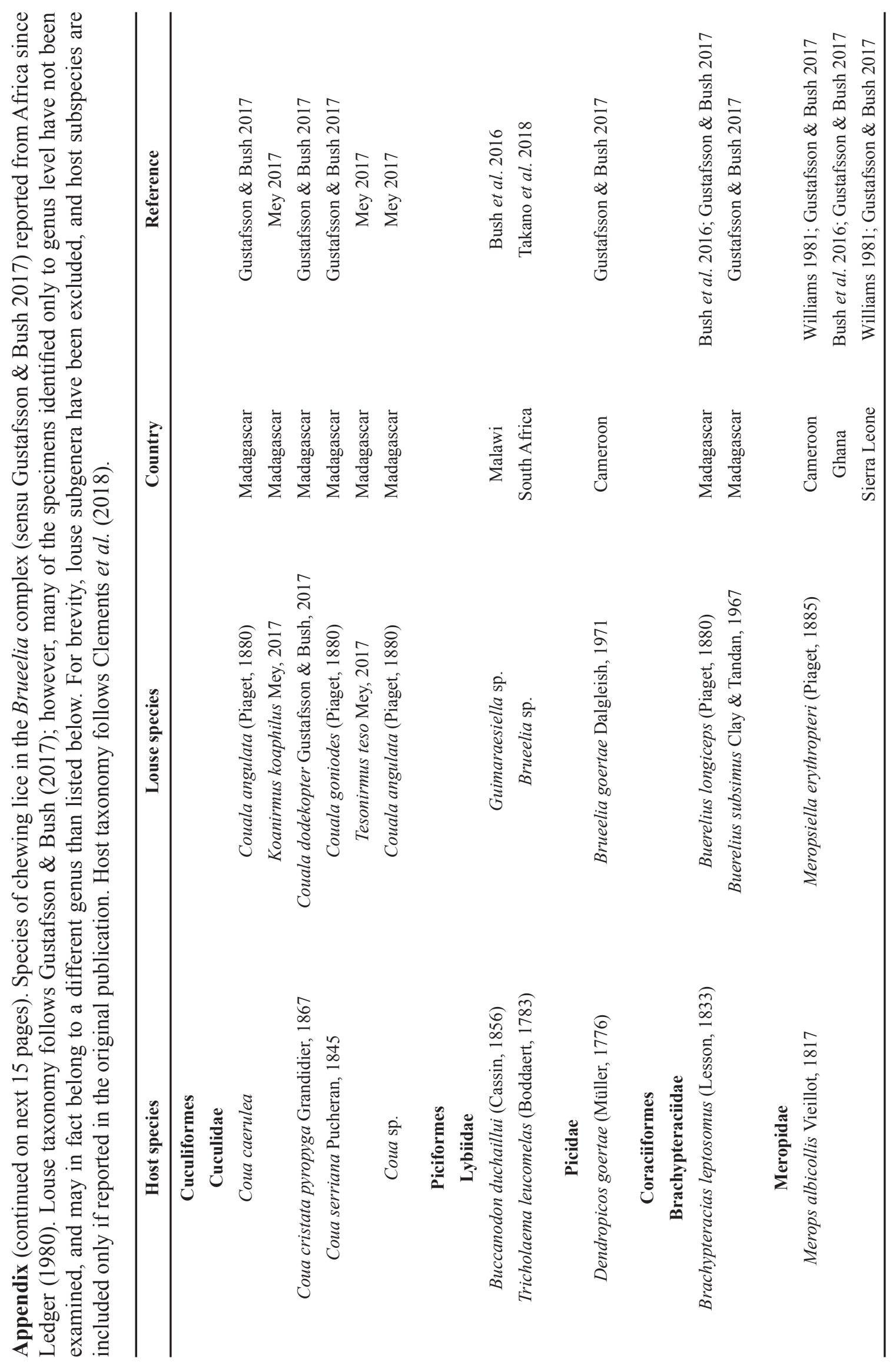




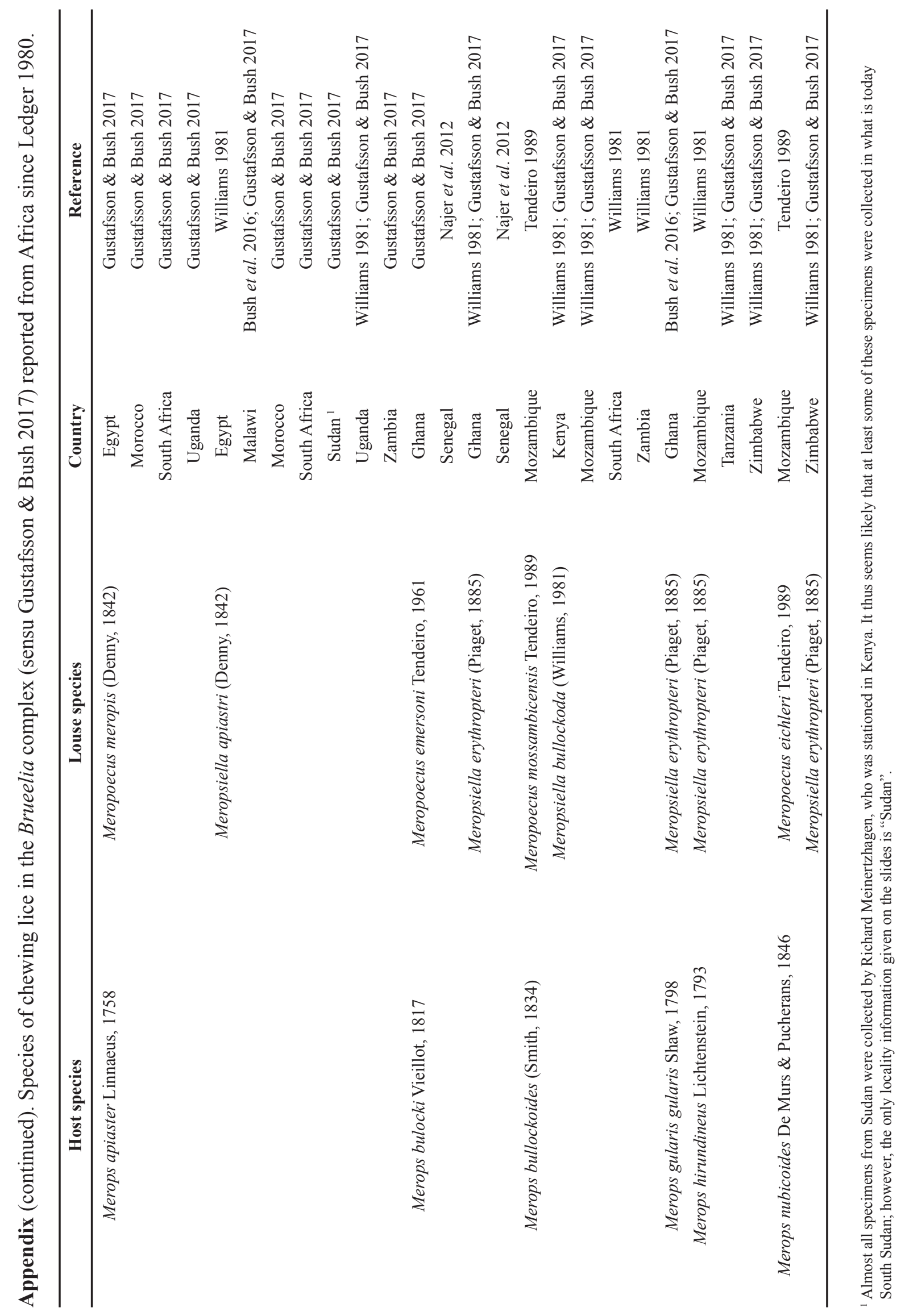




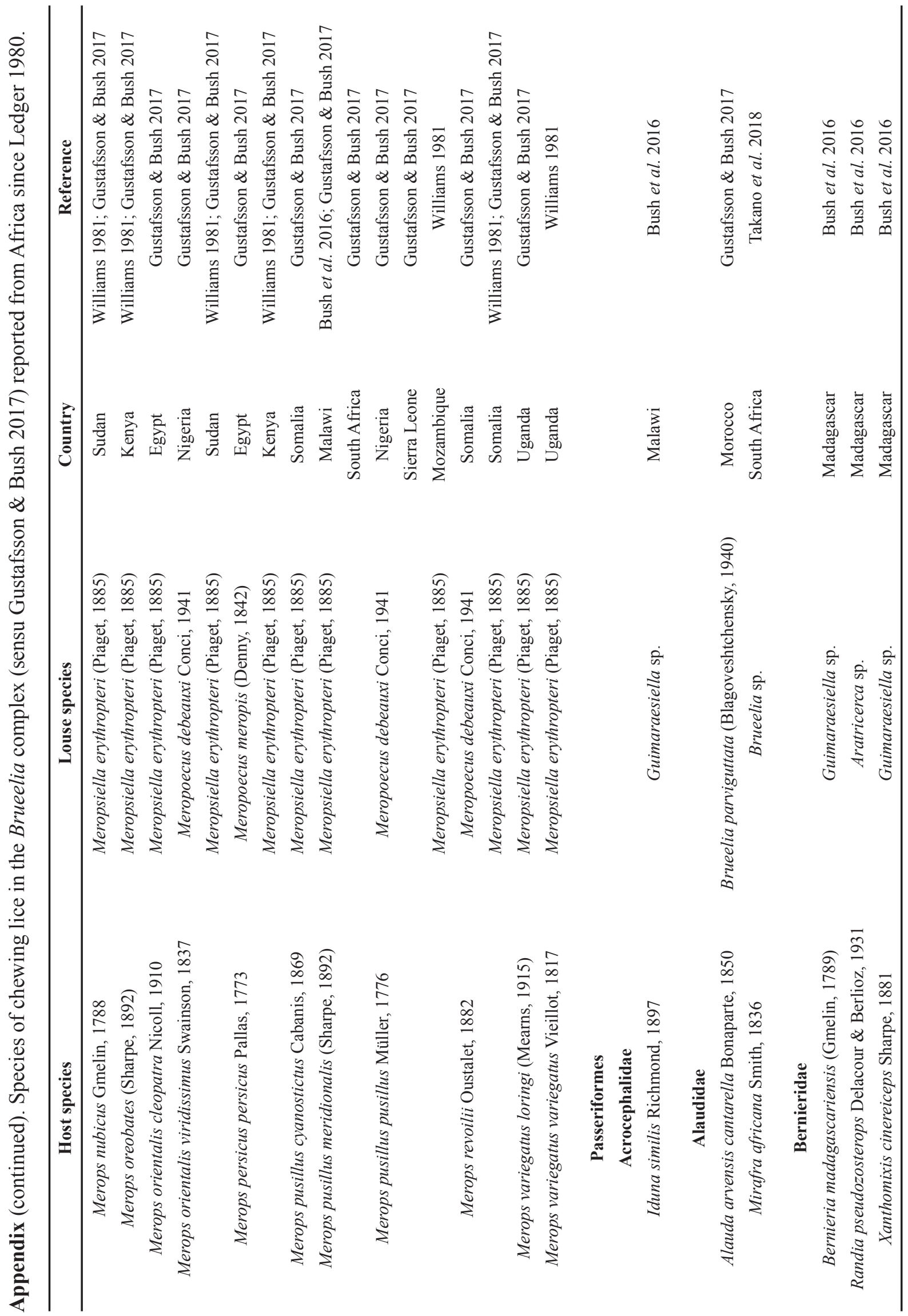




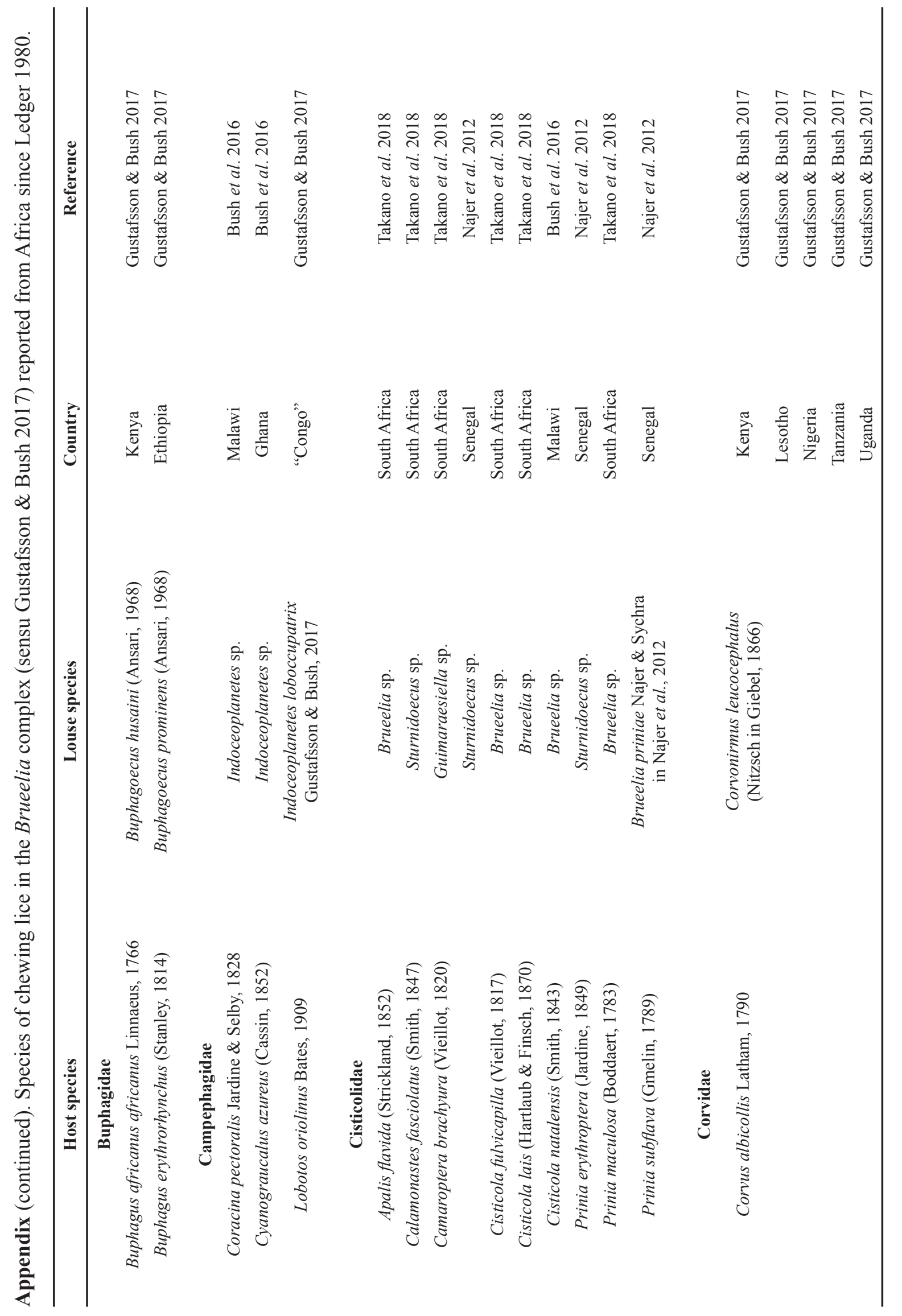




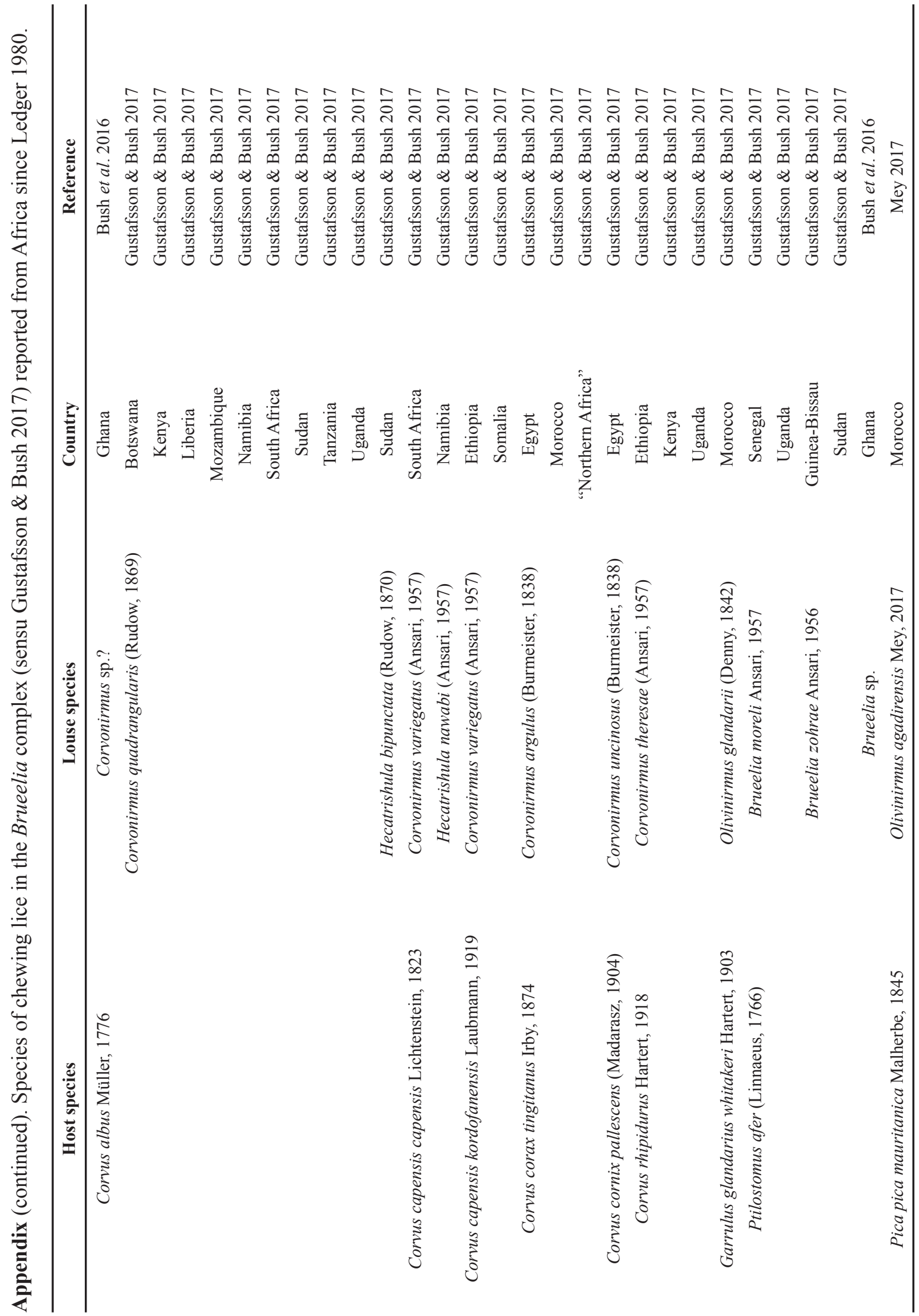




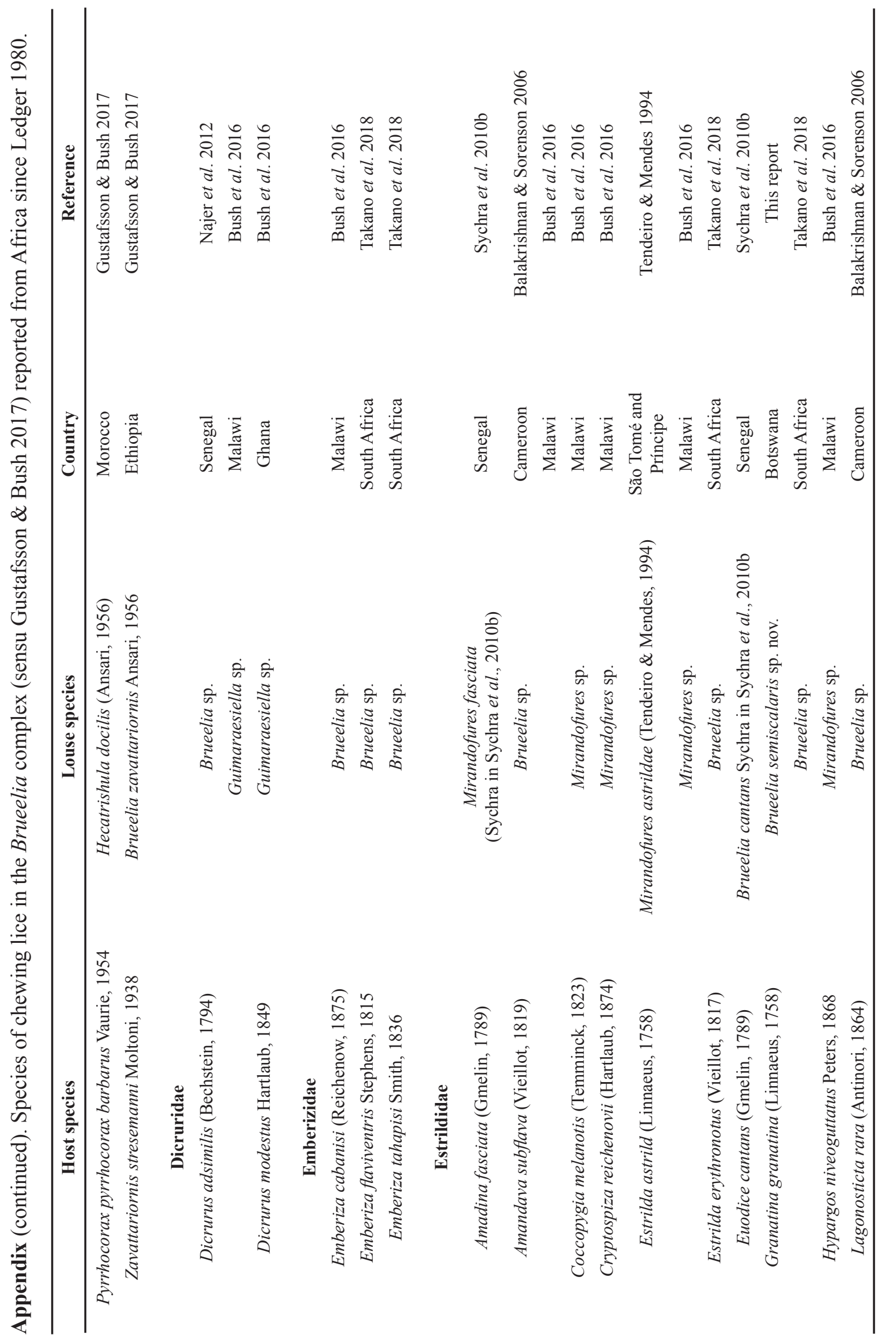




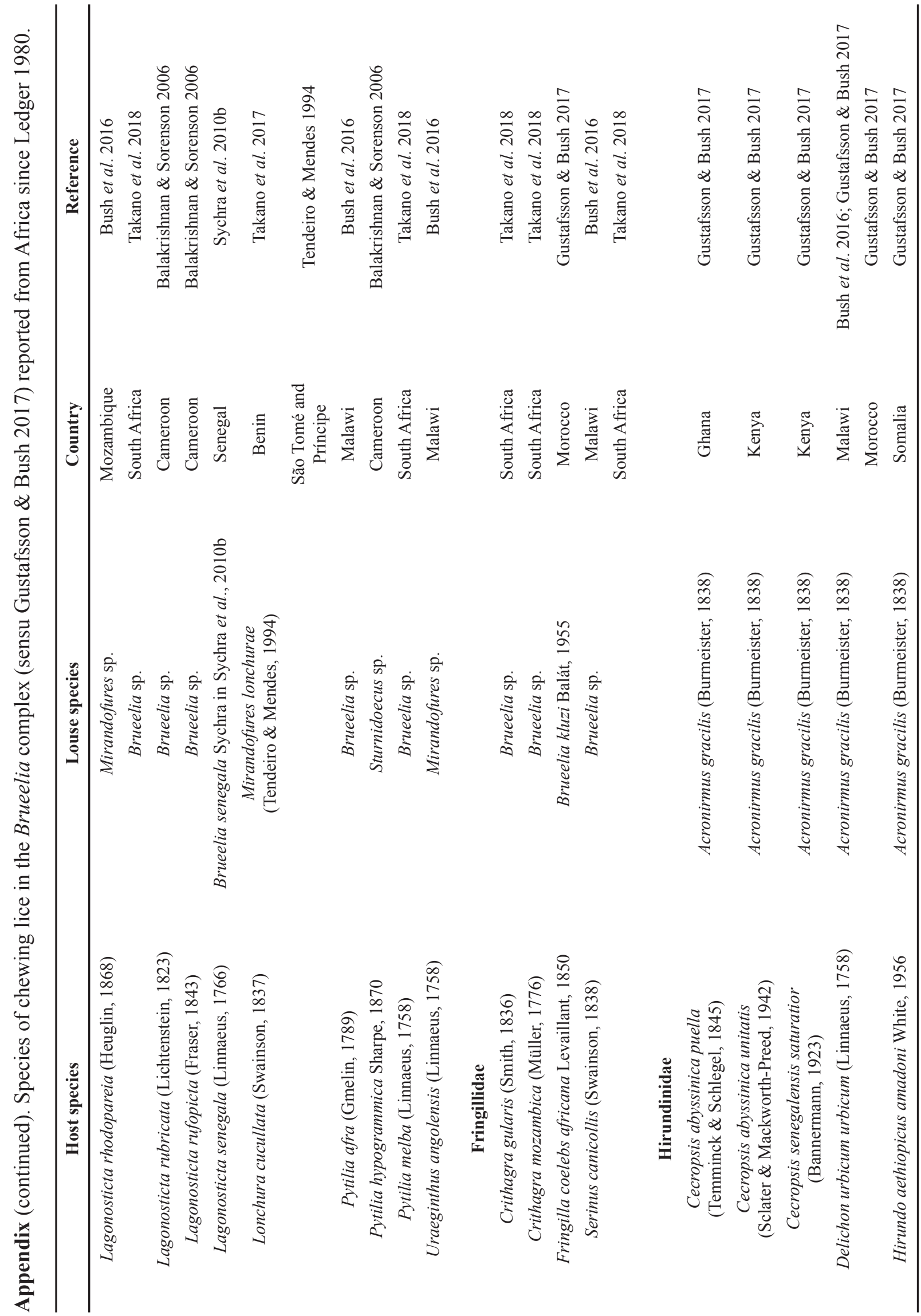




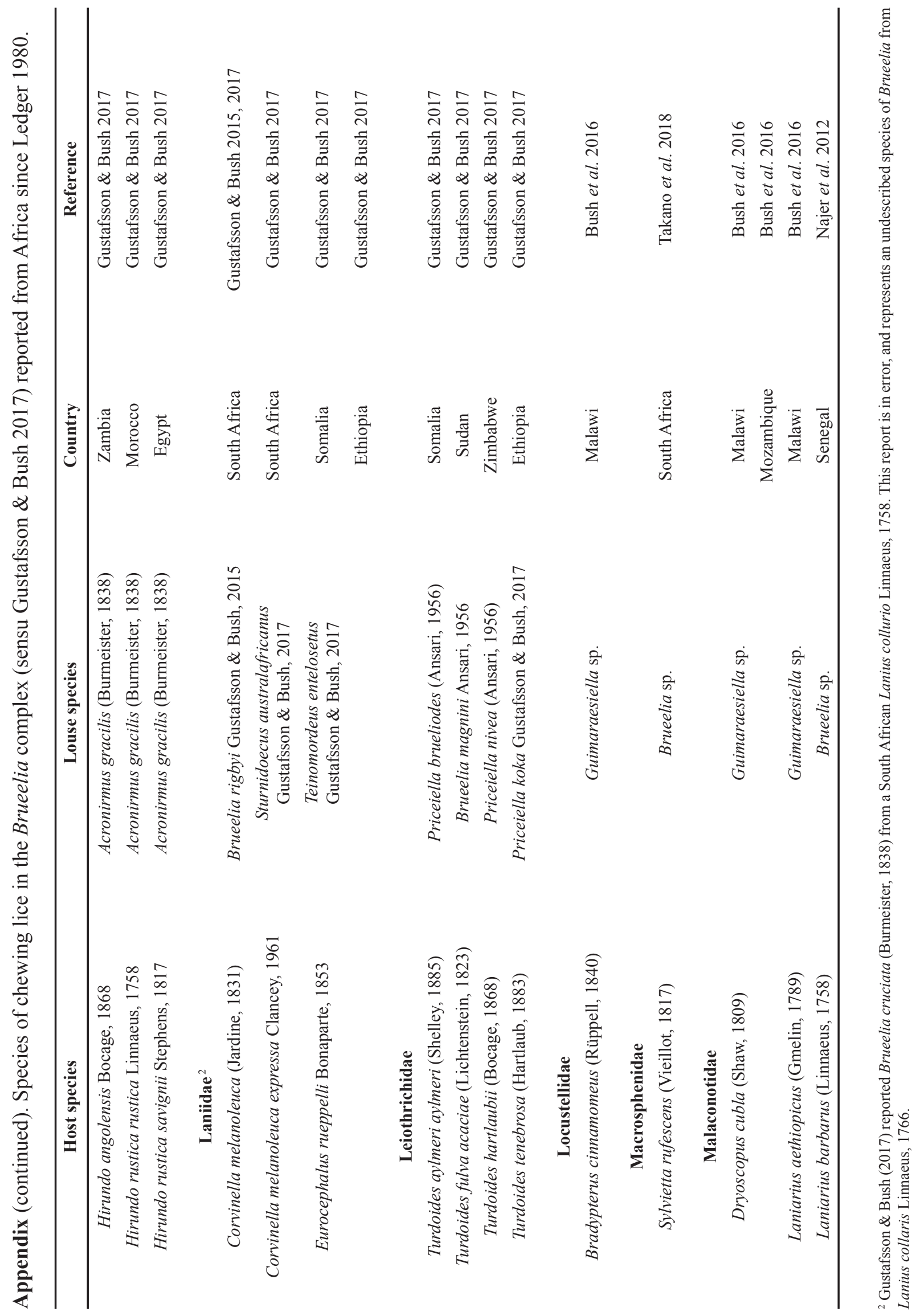




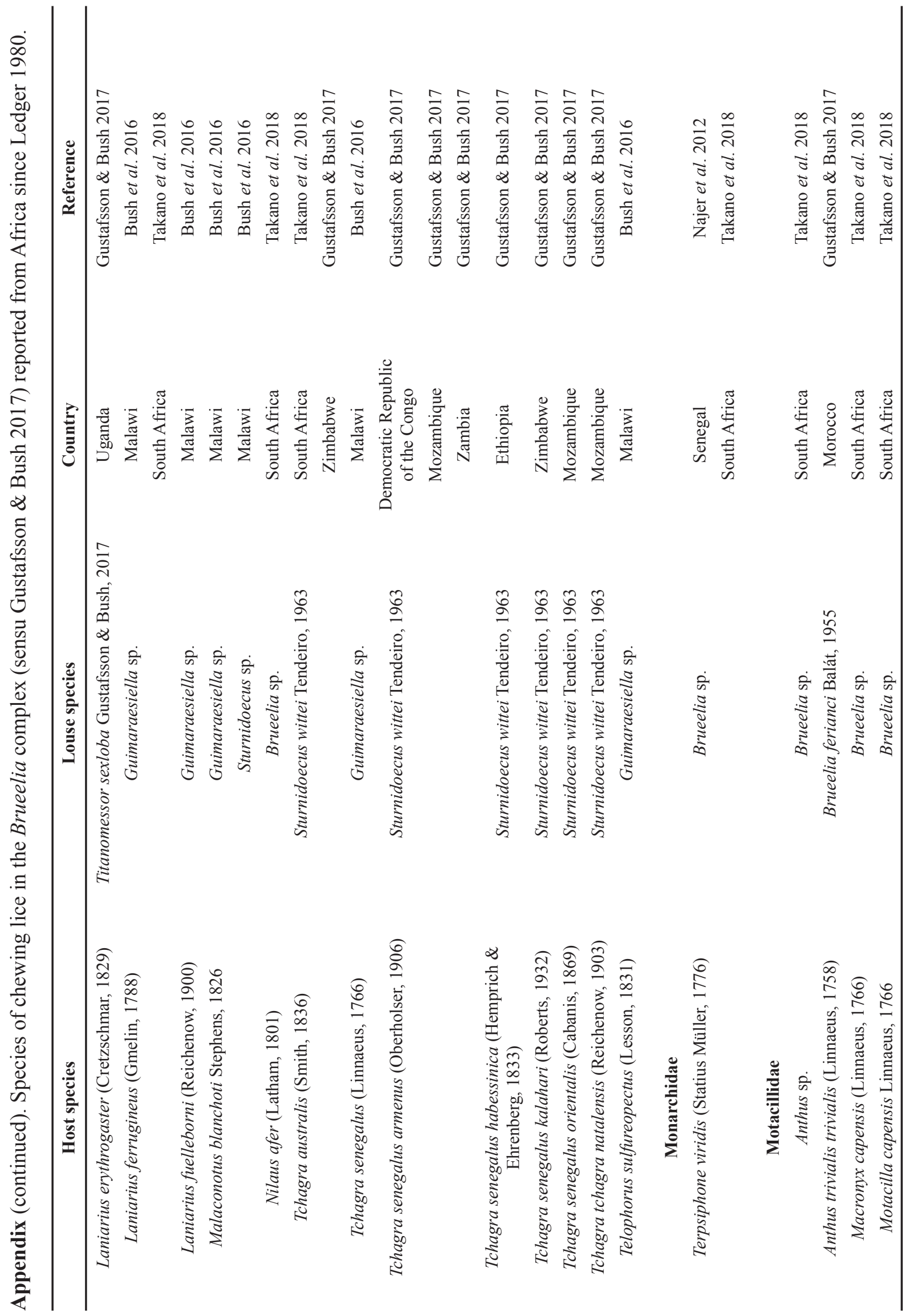




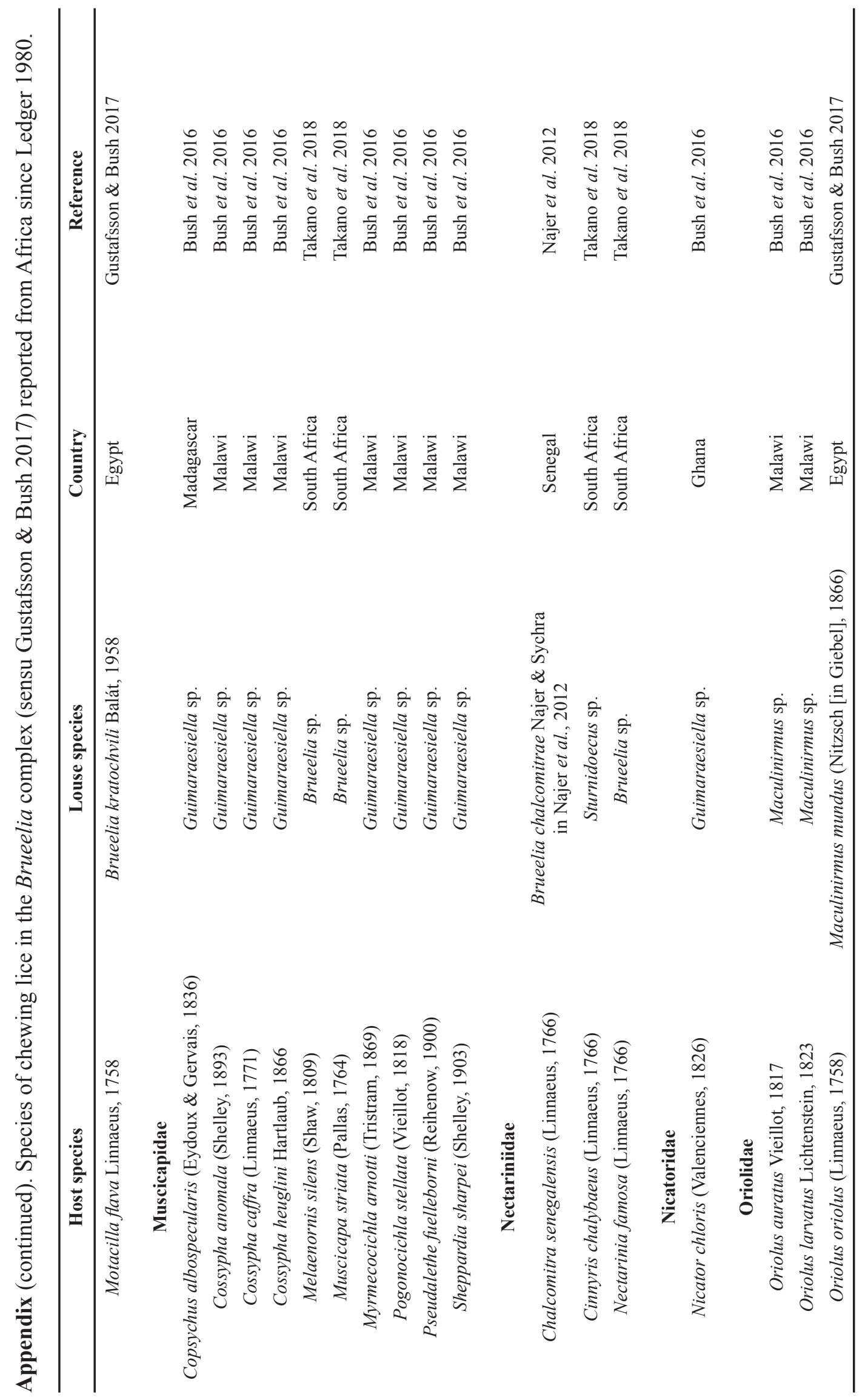




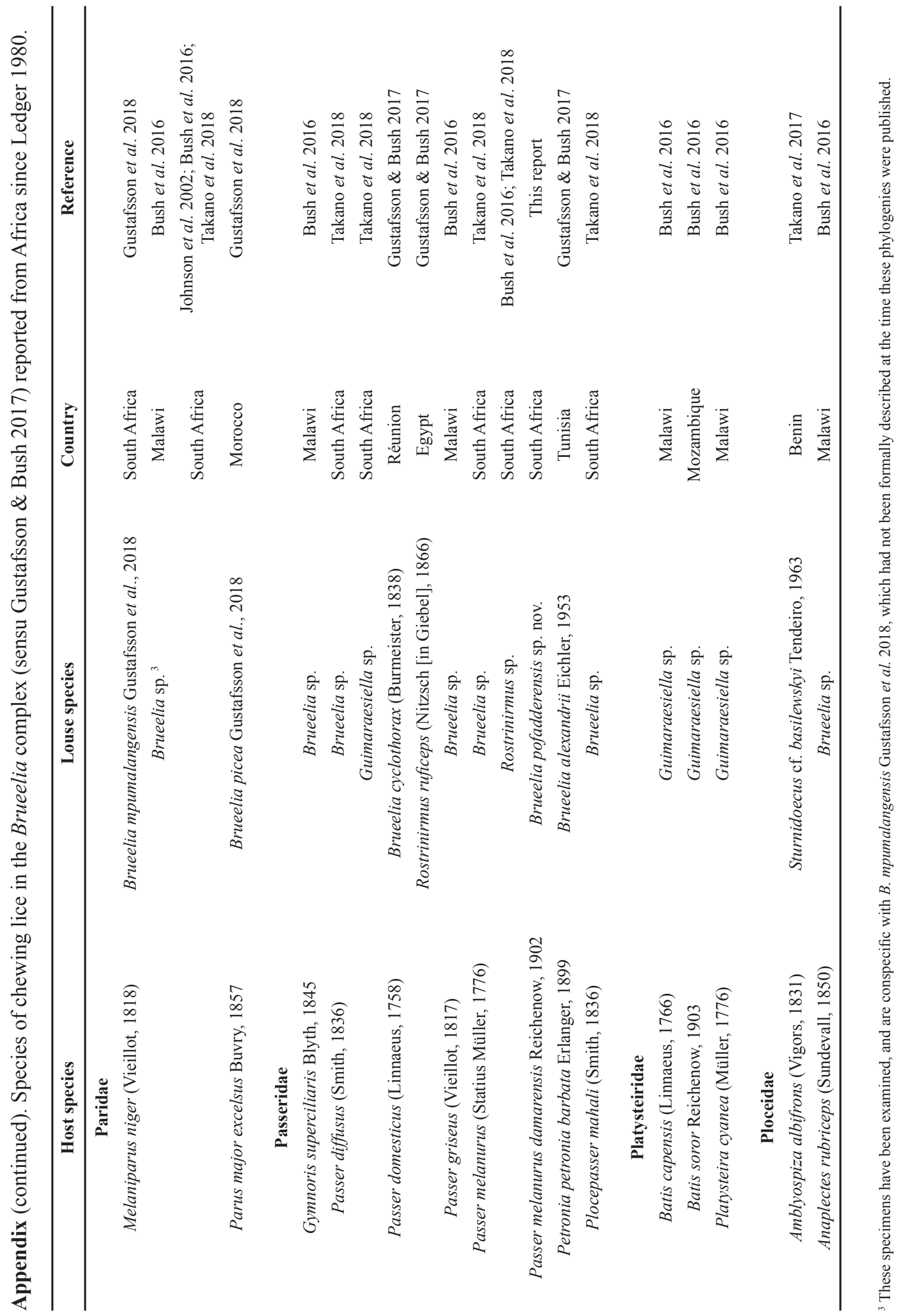




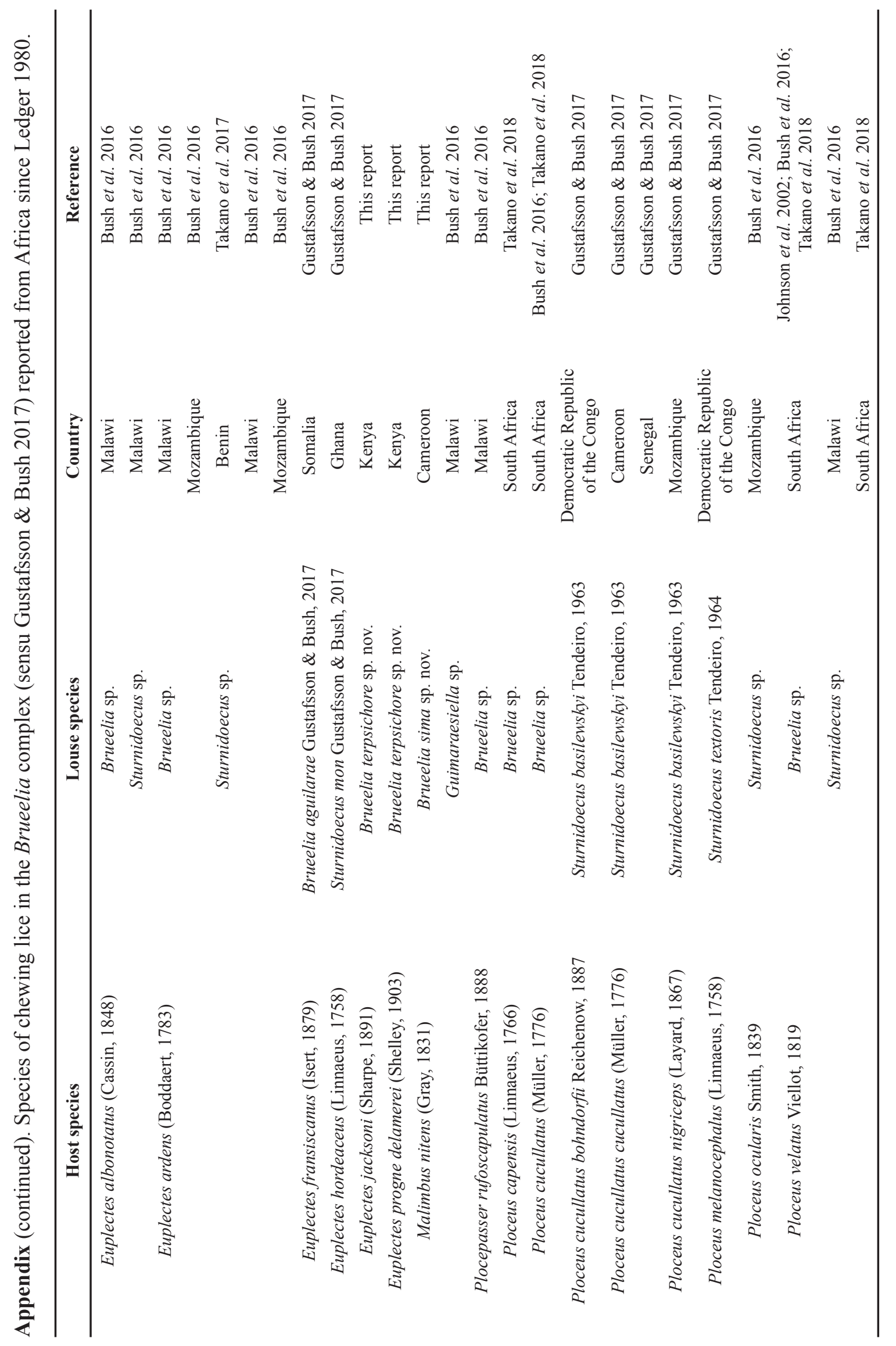




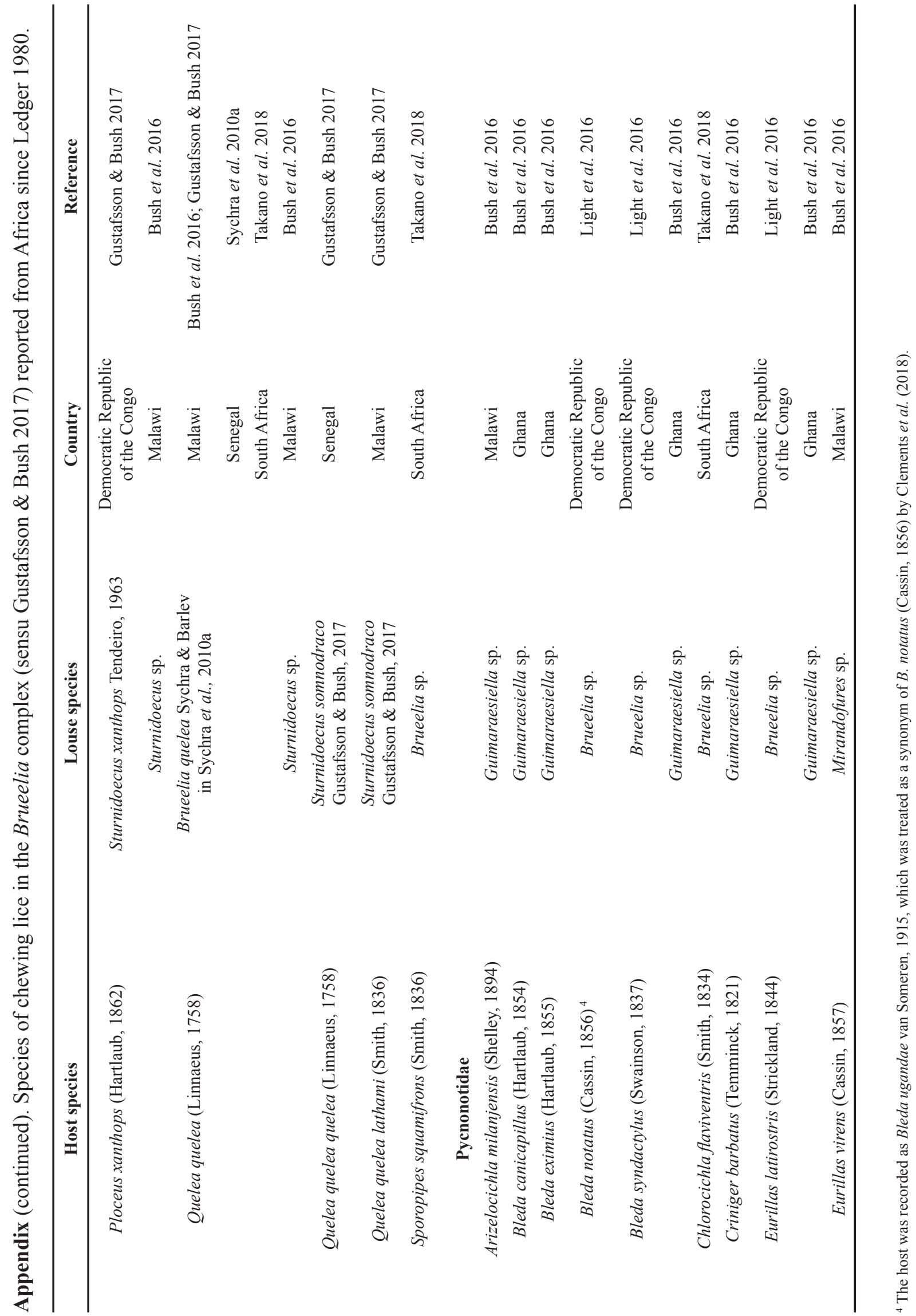




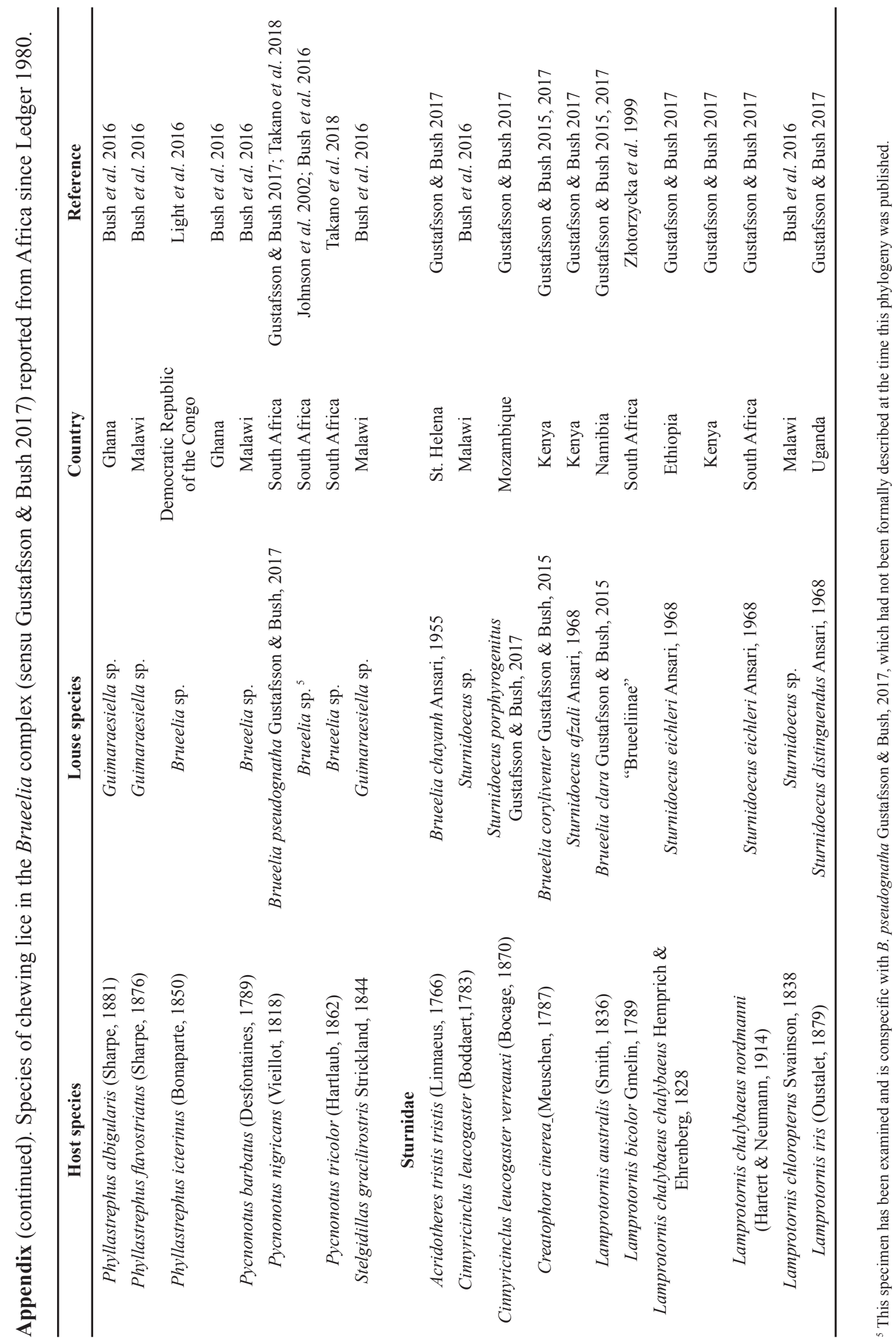




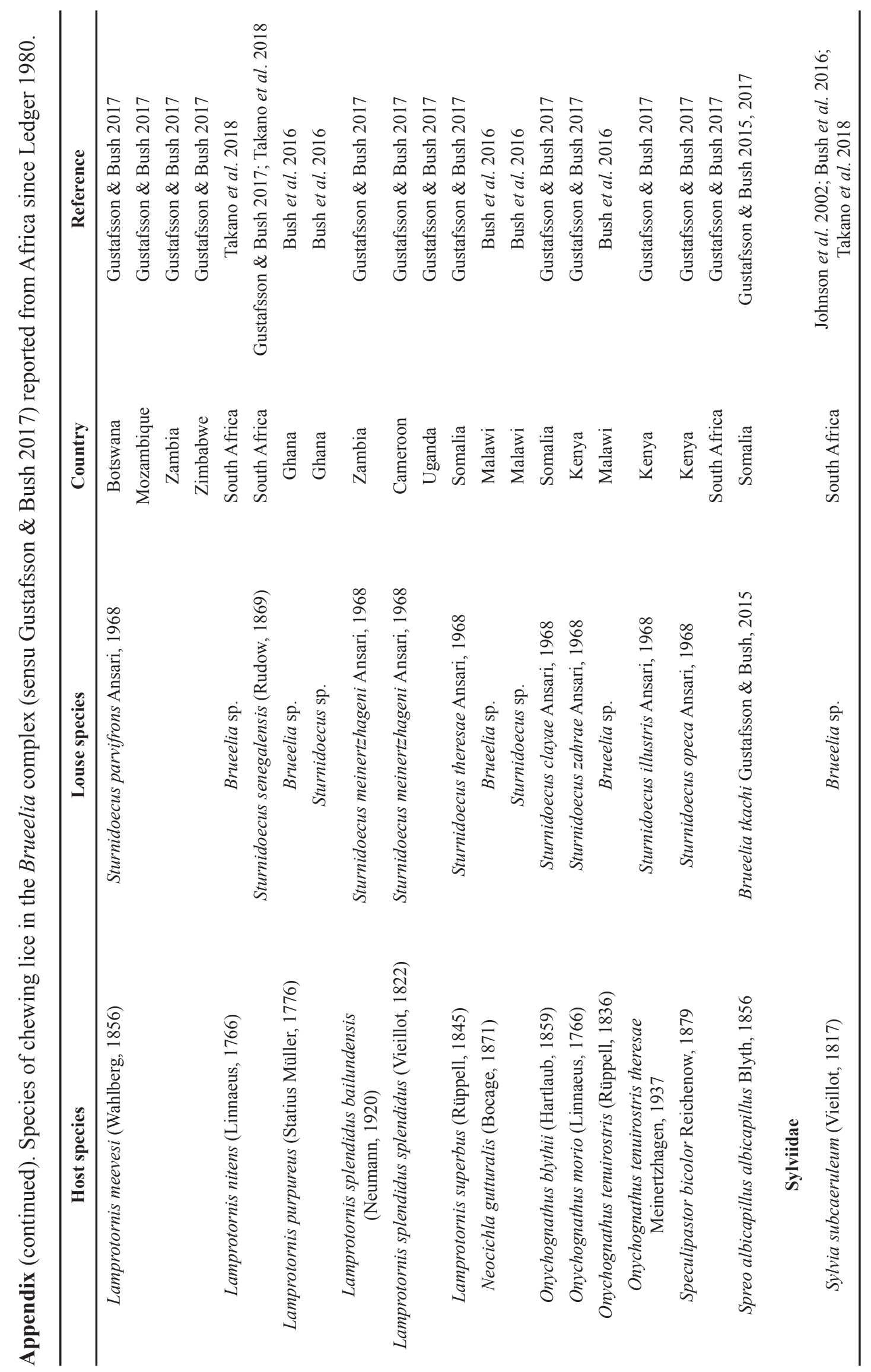




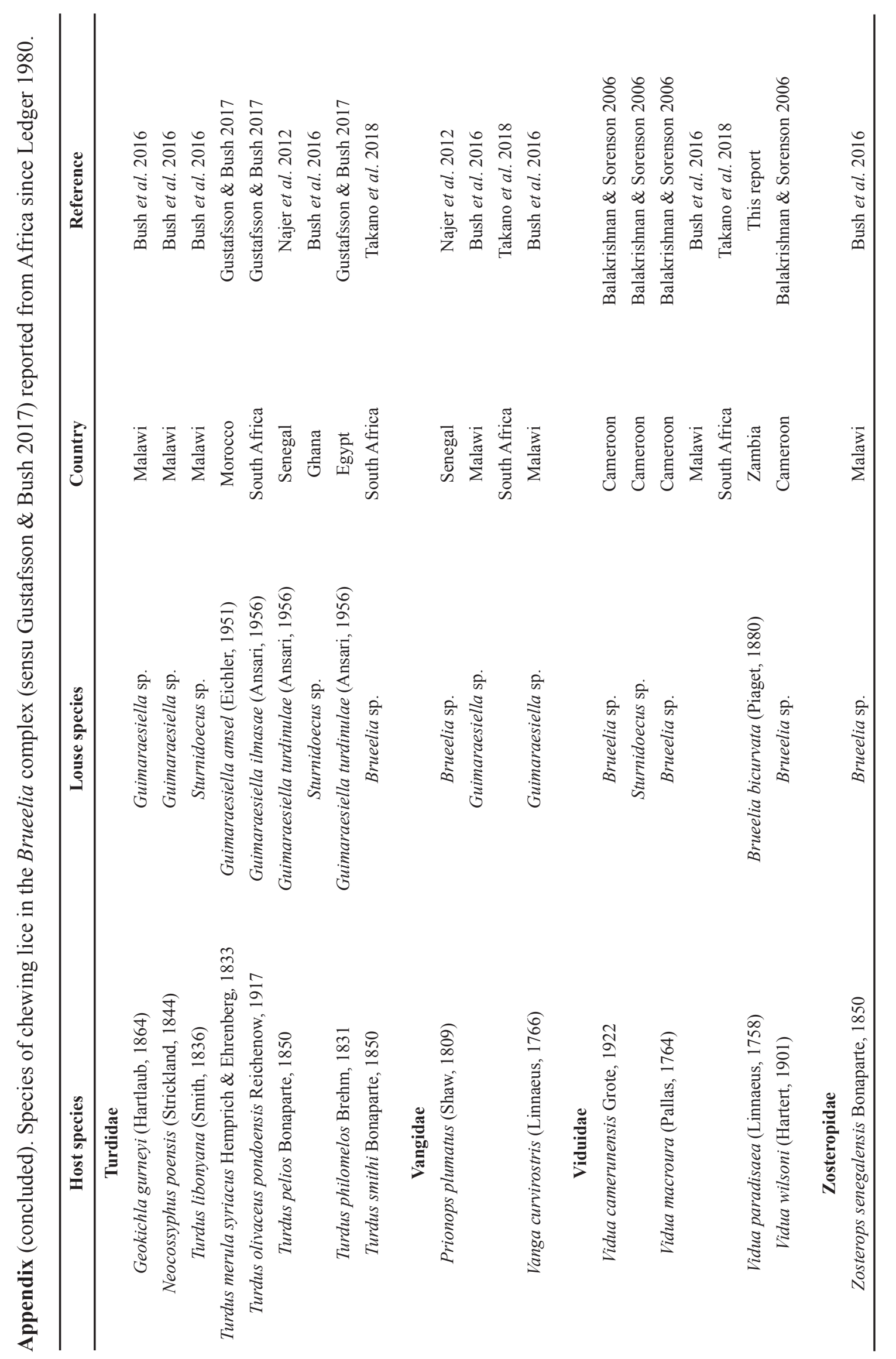

